\title{
Reconstituição paleoambiental da Vereda Carrasco da Raposa, Parque Es- tadual da Serra do Cabral, MG, Brasil, por meio de estudos palinológico e isotópico
}

Em memória de Karin Elise Bohns Meyer (1967-2016)

\author{
Makênia Oliveira Soares GOMES ${ }^{1}$, Karin Elise Bohns MEYER ${ }^{2}$ \& Luiz Carlos Ruiz PESSENDA ${ }^{3}$
}

1 Programa de Pós-Graduação em Geologia, Universidade Federal de Minas Gerais. Av. Antonio Carlos, 6627, CEP 31270-901, Belo Horizonte, MG, Brasil (makenia@ymail.com).

Centro de Pesquisa Professor Manoel Teixeira da Costa/Instituto de Geociências, Universidade Federal de Minas Gerais. Centro de Energia Nuclear na Agricultura, Universidade de São Paulo, Av. Centenário, no 303, Caixa Postal 9613400-970, Piracicaba, SP, Brasil (pessenda@cena.usp.br).

Recebido em 06/2015. Aceito para publicação em 11/2016.

Versão online publicada em 08/05/2017 (www.pesquisasemgeociencias.ufrgs.br)

\begin{abstract}
Resumo - A análise palinológica e de isótopos estáveis (C e N) dos sedimentos da Vereda Carrasco da Raposa (VCR) permitiu a reconstituição paleoambiental dos últimos 21.000 anos AP na região do Parque Estadual da Serra do Cabral (PESC), MG, Brasil. Os resultados mostraram que durante a influência do Último Máximo Glacial, entre 21.150 e 18.850 anos cal. AP, as condições climáticas na Serra do Cabral eram mais frias e com menor umidade do que as atuais; entre 18.850 e 3.550 anos cal. AP o clima passou a ser mais quente e com maior umidade; a partir de 1.650 anos cal. AP houve o estabelecimento da vereda, em condições semelhantes e/ou comparáveis às atuais. Quanto às mudanças fitofisionômicas, foi observada uma sucessão da vegetação com predomínio de Formações Campestres do Cerrado associadas a traços de Formações Florestais na base, Campo Sujo Úmido e Campo Rupestre associados a elementos de mata típicos do Cerrado na porção mediana do perfil; em direção ao topo a partir de 1.650 anos cal. AP houve a instalação da vereda, com a ocorrência dos buritis (Mauritia flexuosa). Os dados isotópicos de C e N indicaram que entre 21.150 e 6.500 anos cal. AP havia uma provável mistura de plantas C3 e C4 como fonte da matéria orgânica sedimentar, mas com o predomínio de plantas $\mathrm{C} 3$, com valores de $\delta 13 \mathrm{C}$ entre $\sim-24 \%$ e e $-21,5 \%$ o. Os valores de C/N $(1,5$ a 11,5) indicaram o predomínio de fitoplâncton e os valores de $\delta 15 \mathrm{~N}(3,5 \%$ o a $\sim 1,0 \%$ ) evidenciaram a mistura de algas e plantas terrestres. Em torno de 3.550 anos cal. AP até o presente a diminuição nos valores de C/N (1,5 a 6) confirmou um ambiente alagado e com maior influência algal na composição da matéria orgânica sedimentar.
\end{abstract}

Palavras-chave: Palinologia, Isótopos estáveis de C e N, Vereda, Paleoclima, Cerrado.

\begin{abstract}
Paleoenvironmental reconstruction of the Carrasco Da Raposa Palm Swamp, Parque Estadual Da Serra do Cabral, Mg, Brazil, By Means Of Palynological And Isotopic STUDIEs. Pollen and stable isotopes ( $\mathrm{C}$ and N) analyses from sediments of Carrasco da Raposa palm swamp (VCR) allowed the paleoenvironmental reconstruction of the last 21,000 years in the region of the Parque Estadual da Serra do Cabral- PESC, MG, Brazil. The results demonstrated that during the influence of Last Glacial Maximum, between 21,150 and 18,850 cal. years BP, the climate conditions in the Serra do Cabral were colder and less humid than in the present; between 1,850 and 3,550 cal. years BP a warmer and wetter climate was recorded; from 1,650 cal. years BP the establishment of the palm swamp occurred in the studied area. Concerning the phytophysionomic changes, a succession of vegetation with a predominance of grassland formations was observed: "Campo Limpo" associated with forest formations at the base, "Campo Sujo" and "Campo Rupestre" associated with Cerrado forest formations in the middle, and the installation of the palm swamp with the presence of Mauritia flexuosa trees towards the top. The isotopic data ( $\mathrm{C}$ and $\mathrm{N}$ ) indicated that between 21,150 and 6,500 cal. years BP, there was a probable mixture of C3 and C4 plants as sedimentary organic matter source, but with the predominance of C3 plants, with $\delta 13 \mathrm{C}$ values of $\sim-24 \%$ to $-21.5 \%$. Values of C/N (1.5 to 11.5 ) suggested the predominance of phytoplankton and the $\delta 15 \mathrm{~N}$ values ( $3.5 \%$ to $\sim 1.0 \%$ ) evidenced the mixture of algae and land plants. Around 3,550 cal. years BP to the present, there has been a decrease in the values of $\mathrm{C} / \mathrm{N}$ (1.5 to $\sim 6)$, confirming a flooded environment with greater influence of algae in the sedimentary organic matter. Keywords: Palynology, estable C and N isotopes, Palm Swamp, Paleoclimate, Cerrado.
\end{abstract}




\section{Introdução}

Estudos palinológicos constituem uma importante ferramenta para interpretações das modificações climáticas e paisagens pretéritas. As análises palinológicas em sedimentos quaternários fornecem valiosas informações sobre a migração das plantas, a composição da vegetação, as mudanças climáticas e consequentes mudanças no ecossistema (Salgado-Labouriau, 1994). É possível reconstruir o tipo de vegetação do passado de uma determinada região a partir do estabelecimento de relações entre os grãos de pólen e esporos e as respectivas plantas as quais eles pertenceram. Portanto uma das mais importantes aplicações da palinologia no Quaternário consiste em estudar a sucessão da vegetação e observar o seu comportamento frente às mudanças climáticas (Salgado-Labouriau, op. cit.).

Neste contexto os trabalhos prévios em palinologia do Cerrado (e.g. Absy et al., 1991; De Oliveira, 1992; Ledru, 1993; Ferraz-Vicentini \& Salgado-Labouriau, 1996; Barberi et al., 2000) oferecem um panorama paleoclimático desde aproximadamente 50.000 anos AP, onde a maior influência das temperaturas mais baixas do Último Máximo Glacial (UMG) sobre os ecossistemas do Planeta se deu no intervalo de tempo em torno de 18.000 a 13.000 anos AP. Na região tropical a temperatura média durante o UMG foi aproximadamente $5^{\circ} \mathrm{C}$ mais baixa que a temperatura média atual (Stute et al., 1995). De acordo com Ab'Saber (1971), no Brasil, o UMG está relacionado a condições climáticas mais secas do que as atuais, decorrentes do declínio do índice de precipitação e da retenção das águas dos oceanos nos pólos Norte e Sul. Já nos períodos interglaciais, houve aumento da umidade, típica do clima tropical atual.

Segundo Pessenda et al. (2004), a análise palinológica quando associada à técnica isotópica e a datação 14C da matéria orgânica do solo é amplamente empregada para a reconstituição da paleovegetação. Apesar disso, existem poucos estudos que utilizam tal associação para interpretação das variações paleovegetacionais, paleoclimáticas e paleoambientais no bioma Cerrado durante o Quaternário (e.g. Horák, 2009; Souza et al., 2013).

A aplicação dos isótopos estáveis de carbono ( $\delta 13 \mathrm{C})$ é baseada na diferença de sinal isotópico das plantas do grupo fotossintético C3 e C4. Plantas C3 compreendem cerca de $85 \%$ das espécies de plantas e consistem de vegetação arbórea e algumas gramíneas que se desenvolvem em regiões úmidas. Elas possuem valores de $\delta 13 \mathrm{C}$ entre -32 $\%$ a $-22 \%$, com uma média de $-27 \%$ o. Já as plan- tas C4 compreendem apenas 5\% das espécies de plantas e são compostas pelas gramíneas que tendem a se desenvolver em ambientes de elevadas temperaturas e luminosidade, com predomínio nas áreas de cerrados e pastagens, ou seja, regiões mais secas. Os valores $\delta 13 \mathrm{C}$ de plantas $\mathrm{C} 4$ variam de $-16 \%$ a $-9 \%$ o com a média de $-13 \%$ o (O'Leary, 1988; Boutton, 1996).

A razão entre os valores elementares do carbono e nitrogênio é utilizada para auxiliar na discriminação de ambas as fontes, já que o carbono está presente em abundância na composição da lignina e celulose das plantas terrestres e o nitrogênio nas proteínas e ácidos nucléicos das algas. Plantas vasculares possuem valores da razão $\mathrm{C} / \mathrm{N}$ em torno de 20 ou mesmo maiores, devido ao alto conteúdo de celulose e lignina, enquanto a matéria-orgânica originada de fitoplâncton apresenta valores menores, entre 4 e 10 (Meyers, 1994).

A fim de permitir o entendimento dos dados obtidos destes métodos analíticos na interpretação paleoambiental e paleoclimática do Quaternário no contexto do Cerrado de Minas Gerais, este trabalho apresenta os resultados do estudo palinológico, das análises dos isótopos estáveis do carbono $(\delta 13 \mathrm{C})$ e nitrogênio $(\delta 15 \mathrm{~N})$ e razão elementar de $\mathrm{C}$ e $\mathrm{N}(\mathrm{C} / \mathrm{N})$ obtidos dos sedimentos da Vereda do Carrasco da Raposa, cuja deposição se deu nos últimos 21.150 anos cal. AP, influenciada pelas variações paleoclimáticas desde o UMG.

\section{2 Área, materiais e métodos}

\section{1 Área de estudo}

A Vereda Carrasco da Raposa está localizada na área do Parque Estadual da Serra do Cabral PESC, $\left(17^{\circ} 40^{\prime} \mathrm{S}, 44^{\circ} 11^{\prime} \mathrm{W}\right)$, entre os municípios de Buenópolis e Joaquim Felício - MG, região centro-norte do estado de Minas Gerais. 0 acesso a partir de Belo Horizonte é feito pela BR-040, sentido Sete Lagoas, até a cidade de Corinto, posteriormente pela BR-135 sentido Montes Claros por mais 117 km até Buenópolis. Joaquim Felício dista $13 \mathrm{~km}$ ao norte de Buenópolis.

\subsubsection{Aspectos geológicos}

A Serra do Cabral está inserida no contexto da evolução geológica regional da Serra do Espinhaço (Fig. 1). Com altitudes que variam entre $900 \mathrm{e}$ $1300 \mathrm{~m}$, a Serra é um divisor de águas entre os rios das Velhas e Jequitaí, ambos afluentes da margem direita do rio São Francisco (Uhlein, 1991).

A Serra do Cabral em Minas Gerais corres- 
ponde a uma grande estrutura braquianticlinal que expõe, no interior do Cráton do São Francisco, os metassedimentos proterozoicos do Supergrupo Espinhaço. À leste da Serra do Cabral ocorre uma depressão sinformal dominada por metassedimentos do Supergrupo São Francisco, em especial o Grupo Bambuí, que recebe o nome de Sinclinal de Buenópolis (Viveiros \& Walde, 1976; Walde, 1978; Uhlein, 1991; Souza Filho \& El-Robrini, 1995).

A região da Serra do Cabral propriamente dita e a região adjacente, o Sinclinal de Buenópolis, representam uma área de exposição de metassedimentos proterozoicos, representados pelo Supergrupo Espinhaço e pelo Supergrupo São Francisco (Fig. 1). Existem na região afloramentos bem preservados da erosão e com baixa taxa de deformação, por ocorrerem em área cratônica (Uhlein et al., 1995).

0 relevo da Serra é formado de chapadas quartzíticas na cota de 900 a $1.000 \mathrm{~m}$, resultante da estrutura braquianticlinal combinada com denudação diferencial entre os quartzitos (ou meta-arenitos) do Supergrupo Espinhaço e os metapelitos (principalmente metassiltitos) do Grupo Bambuí, em cotas de 500 a 600 m. Dentro da Serra existe um relevo irregular, onde alguns picos podem atingir até $1.500 \mathrm{~m}$ de altitude. Este relevo íngreme dentro da Serra permitiu o desenvolvimento de coberturas cenozoicas, de composição arenosa, às vezes conglomeráticas, representadas por colúvios, elúvios e depósitos aluvionares. Localmente desenvolvem-se também coberturas areno-pelíticas ricas em matéria orgânica, de origem lacustre ou fluvial denominadas veredas (Lopes, 2012).

Na Serra do Cabral, o Supergrupo Espinhaço inicia-se com os meta-arenitos da Formação Galho do Miguel, geralmente finos e bem selecionados, com mega-estratificações cruzadas, de ambiente eólico. Para o topo, ocorrem metapelitos da Formação Santa Rita, de ambiente marinho plataformal e os meta-arenitos da Formação Córrego dos Borges, de ambiente litorâneo, que marcam um ciclo transgressivo importante na sedimentação proterozoica. Sobre estes metassedimentos do Supergrupo Espinhaço, em discordância angular, ocorrem metadiamictitos de origem glacial da Formação Jequitaí que marcam uma profunda mudança paleogeográfica e representam a base do Supergrupo São Francisco (Neoproterozoico). Para o topo ocorrem os metassiltitos, calcários e arenitos do Grupo Bambuí. A unidade de topo do Grupo Bambuí, a Formação Três Marias, aflora no núcleo do Sinclinal de Buenópolis, constituída por arenitos de ambiente fluvial (Lopes, 2012).
Os sedimentos siltico-argilosos a arenosos finos da Vereda Carrasco da Raposa estão assentados sobre os quartzitos, metargilitos e metassiltitos do Supergrupo Espinhaço, distribuídos entre os grupos Conselheiro Mata e Diamantina (Fig. 1).

\subsubsection{Clima e vegetação}

O estado de Minas Gerais é influenciado durante todo o ano pela circulação do anticiclone subtropical do Atlântico Sul caracterizado por ventos predominantemente do quadrante nordeste-leste, nos baixos níveis da troposfera. 0 clima da região da Serra do Cabral é quente, úmido, chuvoso a sudoeste da região e moderadamente chuvoso a nordeste, com precipitação média anual entre 1.000 e $1.500 \mathrm{~mm}$ (Geominas, 1996a). As chuvas se concentram nos meses de novembro a março, que constituem a estação chuvosa, enquanto de abril a outubro, na estação seca, são muito escassas. As temperaturas médias anuais variam entre 22 e $24^{\circ} \mathrm{C}$ (Geominas, 1996b) e, segundo a classificação de Köppen, o clima da região é do tipo Aw (Cwa) (EMBRAPA, 2008).

Situado na região centro-norte do estado de Minas Gerais, o PESC, tem uma cobertura vegetacional do tipo Cerrado. É possível identificar principalmente cinco fitofisionomias desde bioma: Campo Rupestre, Cerrado sentido restrito, Formações Campestres do Cerrado e Campo Sujo, Formações Florestais - Matas e Veredas (IEF, 2009).

O Campo Rupestre ocupa aproximadamente $35,27 \%$ da vegetação do PESC (IEF, 2009). Segundo Ribeiro \& Walter (2008) é um tipo de vegetação predominantemente herbáceo-arbustiva, com a presença eventual de arvoretas pouco desenvolvidas de até $2 \mathrm{~m}$ de altura. Na Serra do Cabral, o Campo Rupestre encontra-se formado por um mosaico de vegetações, geralmente acima dos 1.000 m em áreas onde há ventos constantes e variações extremas de temperatura, com dias quentes e noites frias, e no qual o substrato é composto por rochas quartzíticas e solos arenosos. Algumas das espécies mais frequentes pertencem às seguintes famílias e gêneros: Asteraceae (Baccharis, Calea, Lychnophora, Wunderlichia e Vernonia), Bromeliaceae (Dyckia, Tillandsia), Cactaceae (Melocactus, Pilosocereus), Cyperaceae (Bulbostylis, Rhynchospora), Eriocaulaceae (Eriocaulon, Leiothrix, Paepalanthus, Syngonanthus), Gentianaceae (Curtia, Irlbachia), Iridaceae (Sisyrinchium, Trimezia), Labiatae (Eriope, Hyptis), Leguminosae (Calliandra, Chamaecrista, Galactia, Mimosa), Lentibulariaceae (Genlisea, Utricularia), Lythraceae (Cuphea, Diplusodon), Melastomataceae (Cambessedesia, Mico- 


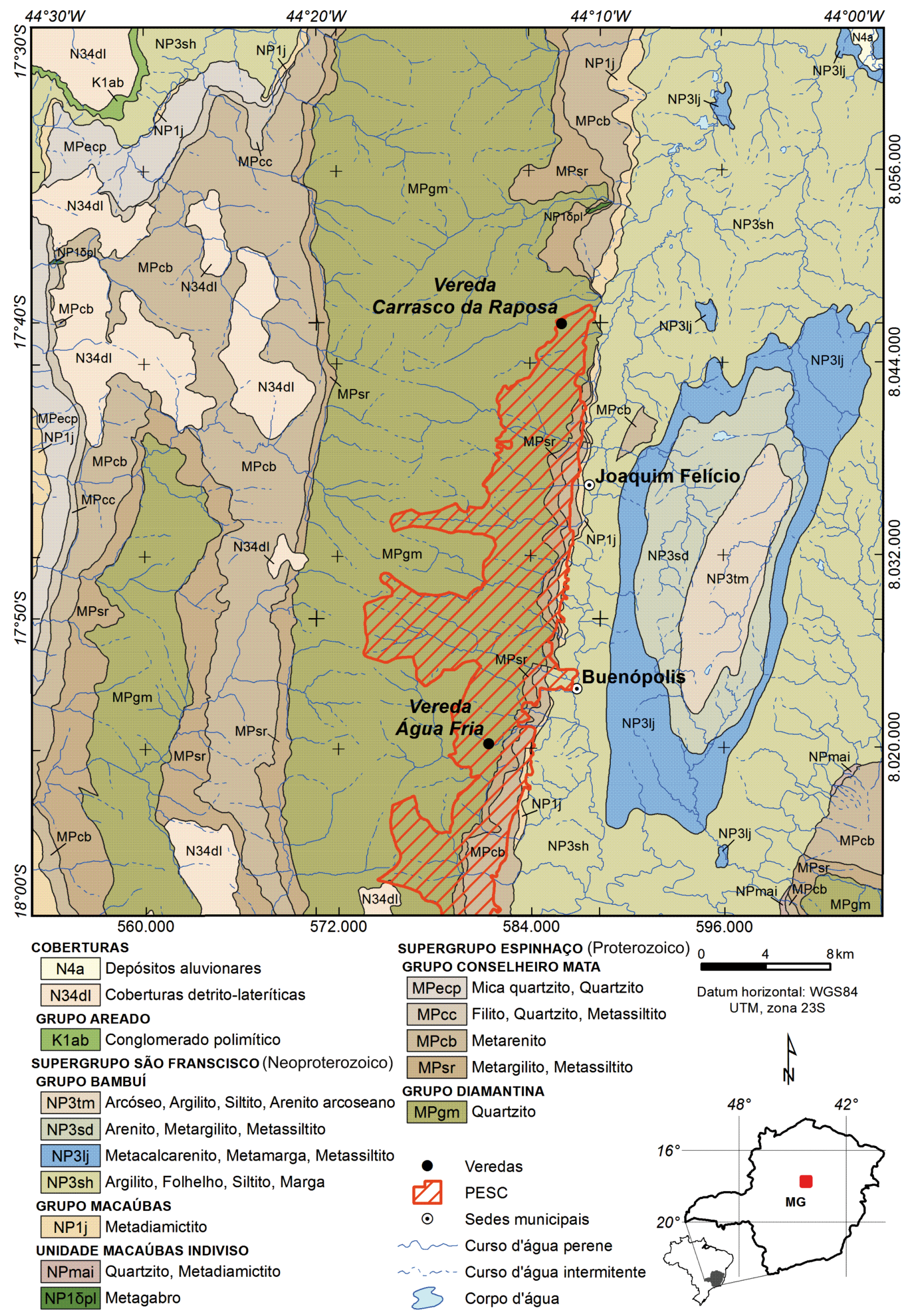

Figura 1. Mapa geológico com a localização da Vereda Carrasco da Raposa e limites do PESC (modificado de Lopes, 2012). Figure 1. Geological Map of Serra do Cabral with the location of Carrasco da Raposa palm swamp and limits of PESC (modified from Lopes, 2012). 
nia, Microlicia), Myrtaceae (Myrcia), Orchidaceae (Cleistes, Cyrtopodium, Epidendrum, Habenaria, Koellensteinia, Pelexia), Poaceae (Aristida, Axonopus, Panicum, Mesosetum, Paspalum, Trachypogon), Rubiaceae (Chiococca, Declieuxia), Velloziaceae (Barbacenia, Vellozia), Vochysiaceae (Qualea) e Xyridaceae (Xyris).

O Cerrado sentido restrito ocupa a segunda maior extensão do PESC, 25,15\% e, dentre suas principais características, está a presença de árvores baixas, inclinadas, tortuosas, com ramificações irregulares e retorcidas, geralmente com evidências de queimadas (IEF, 2009). Os arbustos e subarbustos encontram-se espalhados, com algumas espécies que apresentam órgãos subterrâneos perenes, que permitem a rebrota após queima ou corte. Na Serra do Cabral são encontradas as seguintes espécies arbóreas típicas desta fitofisionomia: Acosmium dasycarpum , Annona coriacea , Aspidosperma tomentosum, Astronium fraxinifolium, Brosimum gaudichaudii, Bowdichia virgilioides, Byrsonima coccolobifolia, Byrsonima crassa, Byrsonima verbascifolia, Caryocar brasilienses, Casearia sylvestris, Connarus suberosus, Curatella americana, Davilla elliptica, Dimorphandra mollis, Diospyros hispida, Eriotheca gracilipes, Erythroxylum suberosum, Hancornia speciosa, Himatanthus obovatus, Hymenaea stigonocarpa, Kielmeyera coriacea, Lafoensia pacari, Machaerium acutifolium, Ouratea hexasperma, Pouteria ramiflora, Plathymenia reticulata, Qualea grandiflora, Qualea multiflora, Qualea parviflora, Roupala montana, Salvertia convallariaeodora, Sclerolobium aureum, Tabebuia aurea, Tabebuia ochracea, Tocoyena formosa, Vatairea macrocarpa e Xylopia aromatica (Ribeiro \& Walter, 2008).

Algumas espécies arbustivas e subarbustivas do Cerrado sentido restrito frequentes na região são: Anacardium humile, Annona monticola, Annona tomentosa, Byrsonima basiloba, Campomanesia pubescens, Cissampelos ovalifolia, Cochlospermum regium, Duguetia furfuracea, Eremanthus glomerulatus, Erythroxylum tortuosum, Esenbeckia pumila, Jararanda decurrens, Kielmeyera rubriflora, Maprounea guianensis, Palicourea rigida, Parinari obtusifolia, Protium ovatum, Sabicea brasiliensis e Vellozia squamata. Dentre as espécies de gramíneas: Axonopus barbigerus, Echinolaena inflexa, Loudetiopsis chrysotrix, Mesosetum loliiforme, Paspalum, Schizachirium tenerum e Trachypogon; além de algumas espécies de orquídeas e bromélias terrestres dos gêneros Cyrtopodium e Habenaria, Bromelia e Dyckia (Ribeiro \& Walter, 2008).

Segundo levantamento florístico realizado pelo IEF (2009), as Formações Campestres do
PESC representam 20,2\% da vegetação total e abrangem diversas variações de campos alagados ou brejosos. 0 Campo Sujo é um tipo fisionômico exclusivamente arbustivo-herbáceo, com arbustos e subarbustos esparsos cujas plantas são menos desenvolvidas que as árvores do Cerrado sentido restrito. Este tipo de vegetação é encontrado em solos rasos, eventualmente com pequenos afloramentos rochosos de pouca extensão (sem caracterizar um Campo Rupestre), ou ainda em solos profundos e de baixa fertilidade (álicos ou distróficos). Em função de particularidades ambientais, o Campo Sujo pode apresentar dois subtipos fisionômicos distintos: Campo Sujo Seco e Campo Sujo Úmido. Na presença do lençol freático profundo, ocorre o Campo Sujo Seco, se o posicionamento do lençol freático é próximo à superfície do solo ocorre o Campo Sujo Úmido.

Segundo Ribeiro \& Walter (2008), as famílias comumente encontradas nesta fitofisionomia são: Poaceae, com espécies dos gêneros Aristida, Axonopus, Echinolaena, Ichnanthus, Loudetiopsis, Panicum, Paspalum, Trachypogon e Tristachya; Asteraceae, com Aspilia, Baccharis, Calea, Chromolaena, Vernonia e Wedelia e Cyperaceae, com os gêneros Bulbostylis e Rhyncosphora. Fazem parte do Campo Sujo Úmido espécies das famílias Leguminosae (Andira, Mimosa), Lamiaceae (Hyptis), Myrtaceae e Rubiaceae, além de várias espécies de outras famílias que se destacam pela floração exuberante na época chuvosa, ou mesmo logo após queimadas, tais como Alstroemeria, Gomphrena officinalis, Griffinia, Hippeastrum e Paepalanthus (Ribeiro \& Walter, 2008).

As Formações Florestais - Matas somam 0,87\% e são representadas na Serra do Cabral por meio de Mata Ciliar, Cerradão, e pequenas ilhas de Mata Atlântica (IEF, 2009). Como atuais espécies arbóreas frequentes na região podem ser citadas: Anadenanthera spp., Apeiba tibourbou, Aspidosperma spp., Casearia spp., Cecropia pachystachya, Celtis iguanaea, Enterolobium contortisiliquum, Inga spp., Lonchocarpus cultratus, Sterculia striata, Tabebuia spp., Tapirira guianensis e Trema micrantha, Protium heptaphyllum, Psychotria carthagenensis, Schefflera morototoni, Styrax camporum, Symplocos nitens, Tapirira guianensis, Virola sebifera, Protium eptaphyllum e Tapirira guianensis (Ribeiro \& Walter, 2008).

As veredas constituem ambientes deposicionais redutores favoráveis à preservação de grãos de pólen, esporos e outros palinomorfos e na área de estudo representam apenas $0,02 \%$ do total da cobertura vegetal. Sua principal característica é a presença da palmeira buriti, Mauritia flexuosa, tá- 
xon de ocorrência específica deste tipo de fitofisionomia, e constitui um dos principais indicadores de ambientes inundados e condições climáticas tropicais (Fig. 2). Sua ocorrência está condicionada ao afloramento do lençol freático; dessa maneira, as veredas exercem papel fundamental na manutenção do sistema hidrológico (Ab'Saber, 1971). Devido à relação direta com as nascentes, as veredas são consideradas áreas de preservação permanente pelo Código Florestal Brasileiro e pela Lei Estadual (14.309 de 20/06/2002), e apesar dessa importância, as mesmas têm sido progressivamente afetadas e destruídas pelas atividades agrícolas e pastoris (IEF, 2009).

\subsection{Material e Métodos}

\subsubsection{Análise palinológica}

Os sedimentos analisados foram coletados de um testemunho de sondagem obtido na Vereda
Carrasco da Raposa (Fig. 2), por meio de amostragem com um testemunhador do tipo Russian, até a profundidade de $100 \mathrm{~cm}$ (Fig. 3). A testemunhagem VCR (Vereda Carrasco da Raposa) recuperou integralmente os $100 \mathrm{~cm}$ e foi dividida em seis camadas da base para o topo: $100 \mathrm{~cm}-89 \mathrm{~cm}, 89 \mathrm{~cm}$ $75 \mathrm{~cm}, 75 \mathrm{~cm}-51 \mathrm{~cm}, 51 \mathrm{~cm}-45 \mathrm{~cm}, 45 \mathrm{~cm}-36 \mathrm{~cm}$ e $36 \mathrm{~cm}-00 \mathrm{~cm}$.

O tratamento químico das amostras sedimentares para a extração dos grãos de pólen foi realizado no Laboratório de Palinologia do Centro de Pesquisa Professor Manoel Teixeira da Costa-CPMTC, Instituto de Geociências da UFMG, de acordo com o método de Faegri \& Iversen (1989), com modificações introduzidas por Colinvaux et al. (1999). 0 método consiste na utilização de HF para eliminação de silicatos, $\mathrm{HCl}$ para dissolução da matriz carbonática, KOH para eliminação dos ácidos húmicos e acetólise: 9 partes de anidrido acético (CH3CO)20:1 parte de ácido sulfúrico (H2SO4).

Cada amostra de $1 \mathrm{~cm} 3$ recebeu uma pasti-

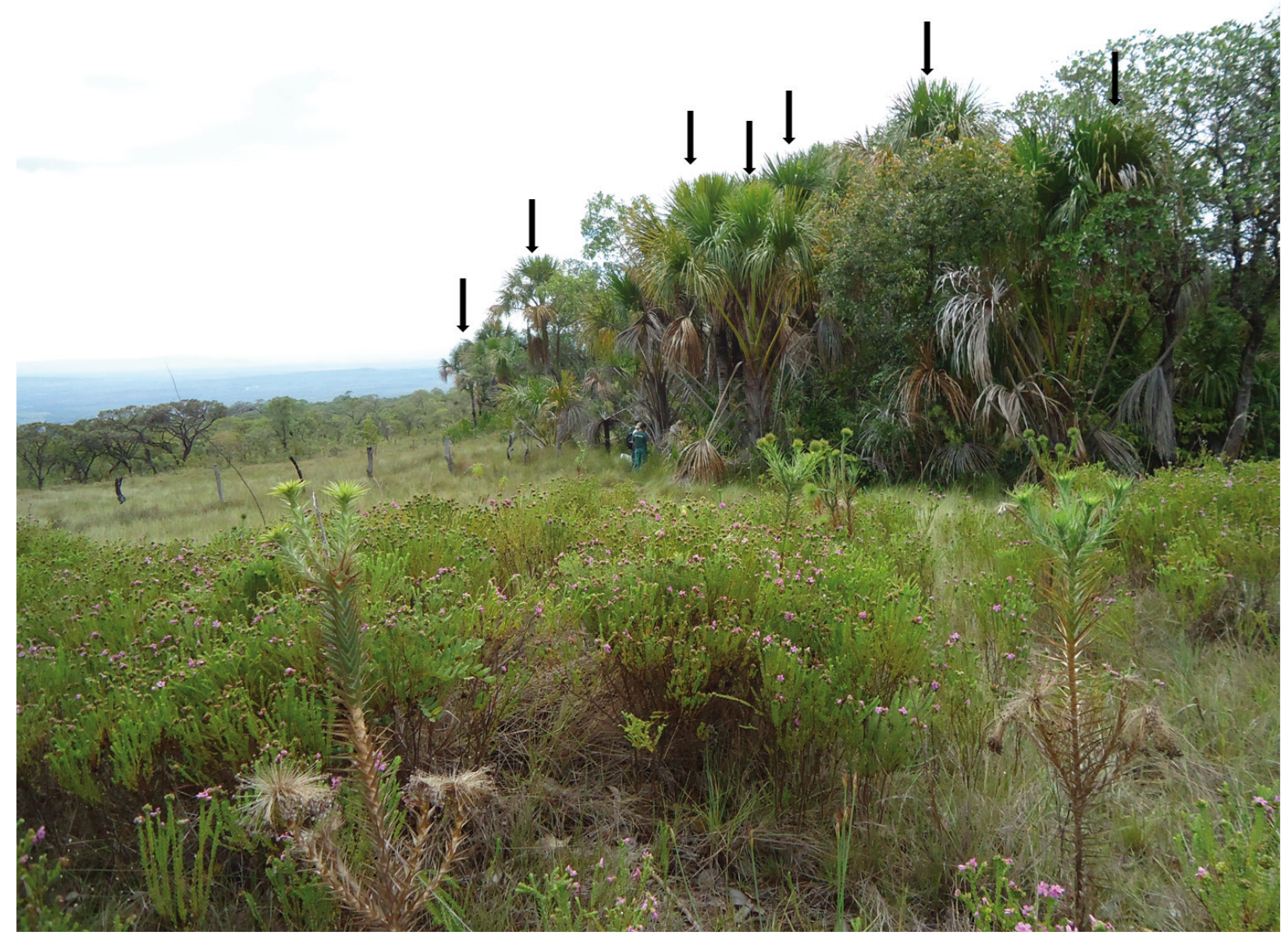

Figura 2. Vista geral da Vereda Carrasco da Raposa no PESC, com flechas indicando a ocorrência dos buritis (Mauritia flexuosa). Figure 2. General view of Carrasco da Raposa palm swamp in PESC, with arrows indicating the occurrence of Mauritia flexuosa trees. 
lha do marcador exótico Lycopodium clavatum, com uma concentração média de 18.584 esporos/ pastilha (lote 17.7745) para determinação da concentração dos grãos de pólen por cm3 (Stockmar, 1971). As lâminas foram montadas em Entellan Merck e depositadas na coleção do Laboratório de Palinologia do CPMTC, sob a numeração MP-P0158 a MP-P-0183.

Os palinomorfos foram descritos e identificados de acordo com a ornamentação e espessura da parede celular e com o número, tipo, posição e forma das aberturas. Na descrição das dimensões e da forma dos grãos foi empregado o método proposto por Salgado-Labouriau (1973). Para a identificação dos esporos de pteridófitos e briófitos e dos grãos de pólen, foi consultada a palinoteca de referência do Laboratório de Palinologia do CPMTC, além de literatura especializada (e.g. Salgado-Labouriau, 1973; Tryon \& Tryon, 1982; Barth \& Melhem,1988; Colinvaux et al., 1999; Punt et al., 2007; Lorente, 2010; Cassino, 2011; Bauermann et al., 2013).

A identificação e a contagem dos palinomorfos foram feitas em um microscópio óptico ZEISS, modelo AXIO IMAGERM2. A análise quantitativa foi feita através da contagem de 300 grãos de pólen de gimnospermas e angiospermas por amostra (Ybert et al., 1992); separadamente foram contados os esporos de Lycopodium clavatum, marcador exótico. Os dados são apresentados em forma de diagramas de porcentagem e concentração dos diferentes palinomorfos, gerados no Programa Tilia, Tilia Graph e CONISS (Grimm, 1987).

\subsubsection{Datação ${ }^{14} \mathrm{C}$}

As datações ${ }^{14} \mathrm{C}$ foram feitas em cinco amostras sedimentares (VCR23, VCR18, VCR13, VCR07 e VCR05) "in natura" do testemunho VCR, pela técnica AMS (Accelerator Mass Spectrometry) no Beta Analytic Radiocarbon Dating Laboratory, Miami, EUA. A profundidade das amostras datadas, as idades ${ }^{14} \mathrm{C}$ convencionais obtidas, os intervalos de calibração e as idades médias calibradas fornecidas pelo programa Calib 7.0.2 (Stuiver \& Reimer, 1993) são mostrados na tabela 1 , assim como uma estimativa das taxas de sedimentação ao longo do perfil.

Através dos resultados obtidos pelas análises citadas acima, foi observada uma variação na dinâmica deposicional da vereda ao longo do tempo. Os primeiros $59 \mathrm{~cm}$ de sedimento da base até a porção mediana do testemunho foram depositados em cerca de 14.650 anos, enquanto os $41 \mathrm{~cm}$ até o topo foram depositados em aproximadamen- te 6.500 anos. Isto indica taxas de sedimentação variáveis, as quais foram de $0,27 \mathrm{~cm} / 100$ anos da base até a porção mediana e $0,66 \mathrm{~cm} / 100$ anos em direção ao topo.

\subsubsection{Análise isotópica}

Um total de 26 amostras sedimentares coletadas a cada $4 \mathrm{~cm}$ foram preparadas no Laboratório de Isótopos Estáveis do Centro de Energia Nuclear na Agricultura da Universidade de São Paulo (CENA/USP), com determinação em Espectrômetro de Massa acoplado a um Analisador Elementar ANCA-SL, Europa Scientific. Para tanto, as amostras foram secas em estufa a $40^{\circ} \mathrm{C}$, homogeneizadas em almofariz de ágata e pesadas em cápsulas de estanho $\left(\sim 1 \mathrm{mg}\right.$ para $\delta^{13} \mathrm{C}$ e $\sim 5 \mathrm{mg}$ para $\left.\delta^{15} \mathrm{~N}\right)$ de acordo com o método descrito por Pessenda et al. (1996). Os teores de Carbono Orgânico Total - COT (\%) e Nitrogênio-total - NT (\%) juntamente com os valores de $\mathrm{C} / \mathrm{N}, \delta^{13} \mathrm{C}(\% 0)$ e $\delta^{15} \mathrm{~N}(\%)$ são apresentados na figura 9 .

\section{Resultados}

\subsection{Perfil sedimentar}

A testemunhagem VCR recuperou integralmente os $100 \mathrm{~cm}$ perfurados com o predomínio de intercalações de sedimentos siltico-argilosos a arenosos finos (Fig. 3). A sequência sedimentar foi dividida em seis camadas assim designadas da base para o topo: camada argilo-arenosa de coloração cinza-clara $(100 \mathrm{~cm}-89 \mathrm{~cm})$, camada síltico-argilosa de coloração preta $(89 \mathrm{~cm}-75 \mathrm{~cm})$, camada argilo-arenosa de coloração cinza-escura (75 cm-51 cm), camada síltico-argilosa de coloração preta $(51 \mathrm{~cm}-45 \mathrm{~cm})$, camada argilo-arenosa de coloração cinza-clara $(45 \mathrm{~cm}-36 \mathrm{~cm})$ e no topo da sequência sedimentar uma camada síltico-argilosa de coloração preta $(36 \mathrm{~cm}-00 \mathrm{~cm})$.

\subsection{Datação ${ }^{14} \mathrm{C}$}

Os dados obtidos a partir das datações convencionais e idades calibradas (Tabela 1) revelaram uma variação na dinâmica deposicional da vereda ao longo do tempo. Enquanto os $42 \mathrm{~cm}$ mais profundos $(90 \mathrm{~cm}$ a $48 \mathrm{~cm}$ ) foram depositados em cerca de 14.650 anos cal. AP, os $32 \mathrm{~cm}$ da porção mediana do testemunho até o topo, foram depositados em aproximadamente 4.850 anos cal. AP. Na porção basal do testemunho $(100 \mathrm{~cm}-89 \mathrm{~cm})$, uma camada argilo-arenosa de coloração cinza-clara foi desprezada por não apresentar material adequado 


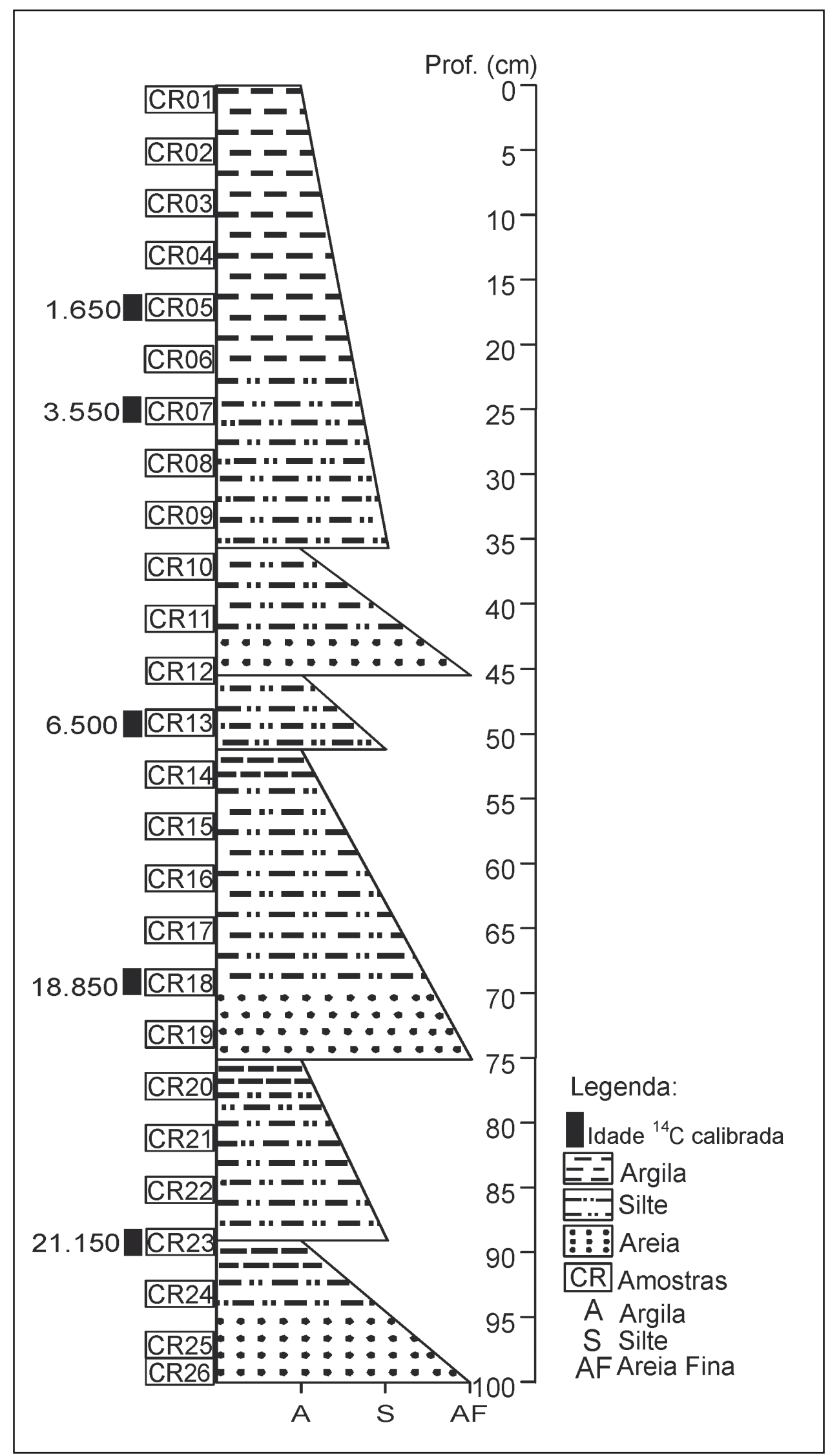

Figura 3. Perfil sedimentar da Vereda Carrasco da Raposa, com a profundidade das 26 amostras, utilizadas na análise palinológica (*amostras datadas por 14C e calibradas no Calib 7.0.2, Stuiver \& Reimer, 1993).

Figure 3. Sedimentary profile of Carrasco da Raposa palm swamp, with depth of 26 samples used in pollen analysis ( ${ }^{*}$ samples dated by $14 C$ and calibrated in Calib 7.0.2, Stuiver \& Reimer, 1993) 
às análises polínica e isotópica.

\subsection{Análise palinológica}

Três intervalos polínicos foram estabelecidos a partir da análise de agrupamento obtida com o programa Coniss (Grimm, 1987): Intervalo VCRI, Intervalo VCRII e Intervalo VCRIII (Figs. 4 a 6).

A interpretação do significado paleoambiental e paleoclimático destes intervalos foi feita com base na variação da frequência dos palinomorfos em conjunto com os dados obtidos na análise isotópica. Os táxons foram identificados (Apêndice 1) e agrupados de acordo com a fitofisionomia a qual pertencem atualmente (Fig. 7 e 8). A associação das diferentes espécies encontradas na Vereda Carrasco da Raposa à determinada fitofisionomia, seguiu principalmente o trabalho de Ribeiro \& Walter (2008).

A seguir são apresentadas as principais características dos conjuntos polínicos em cada um dos intervalos.

\subsubsection{Intervalo VCRI (100 - $72 \mathrm{~cm}$, amostras VCR26 a VCR19, de 21.150 a 18.850 anos cal. AP)}

A flora herbáceo-arbustiva neste intervalo apresentou elevado percentual, representada por Poaceae (51\%) e Cyperaceae (26\%). Em menores porcentagens foram identificados: Tipo Baccharis (4\%), Begonia (2\%), Brosimum gaudichaudii $(1,7 \%)$, Tipo Borreria (1,0 \%), Tipo Gomphrena $(0,8 \%)$, Solanum $(0,5 \%)$, Richardia $(0,2 \%)$, Tipo Aspilia $(0,2 \%)$, Tipo Vernonia $(0,2 \%)$, Polygala $(0,1 \%)$, Drosera $(0,11 \%)$ e Eryngium $(0,1 \%)$. A soma destes táxons foi de $88 \%$ do total do registro polínico no intervalo.

Os elementos arbóreos totalizaram 12\%, representados por grãos de pólen de Roupala $(1,8 \%)$, Podocarpus $(1,8 \%)$, Ilex $(1,7 \%)$, Anacardiaceae Tipo $1(1,2 \%)$, Euplassa (1\%), Tipo Butia (1\%), Cecropia (0,8\%), Ericaceae Tipo 1 (0,4\%), Bignoniaceae Tipo $1(0,4 \%)$, Daphnopsis $(0,4 \%)$, Tipo Eremanthus (0,3\%), Myrsine (0,2\%), Schefflera $(0,1 \%)$, Drymis brasiliensis $(0,07 \%)$ e Araliaceae Tipo $1(0,03 \%)$.

Foram registrados 1.597 palinomorfos pertencentes a pteridófitos, algas e fungos que não foram incluídos na contagem polínica para a reconstituição paleovegetacional. No entanto estão aqui citados com o objetivo de complementar as informações paleoambientais.

Dentre os pteridófitos o gênero Blechnum foi predominante, Schizae, Lycopodiella cernua, Lycopodiella alopecuroides, Cyathea Tipo 1, Pteris e Polypodium foram identificados em menores concentrações. As algas foram representadas principalmente por Spyrogira e Debarya com maior representatividade, seguidas por Mougeotia e Zygnema.

\subsubsection{Intervalo VCRII (72 - $26 \mathrm{~cm}$, amostras VCR19 a VCR07, de 18.850 a 3.550 anos cal. AP)}

Neste intervalo a alta porcentagem de Cyperaceae e Poaceae (63\%) se repetiu. Permaneceram no registro dos elementos herbáceos, Tipo Baccharis (4\%), Tipo Borreria (3,5\%), Solanum $(1,5 \%)$, Tipo Gomphrena (1,1\%), Brosimum gaudichaudii $(0,7 \%)$, Richardia $(0,4 \%)$ e Eryngium $(0,1 \%)$. Fo-

Tabela 1. Amostras datadas, profundidade das amostras, código do laboratório, idades 14C convencionais, intervalos de calibração das idades 14C, idades médias calibradas e estimativa das taxas de sedimentação.

Table 1. Dated samples, depth of samples, laboratory code, conventional 14C ages, calibration intervals of 14C ages, average calibrated ages and sedimentation rates estimate.

\begin{tabular}{|c|c|c|c|c|c|c|}
\hline Amostras & $\begin{array}{l}\text { Profundidade } \\
\text { (cm) }\end{array}$ & $\begin{array}{c}\text { Código/ } \\
\text { Laboratório }\end{array}$ & $\begin{array}{c}\text { Idade }{ }^{14} \mathrm{C} \\
\text { convencional } \\
\text { (anos AP) }\end{array}$ & $\begin{array}{c}\text { Idade calibrada } \\
2 \sigma(95 \% \\
\text { probabilidade) } \\
\text { Intervalos (anos } \\
\text { cal. AP) }\end{array}$ & $\begin{array}{c}\text { Idade } \\
\text { média }\left({ }^{14} \mathrm{C}\right)\end{array}$ & $\begin{array}{c}\text { Taxa de } \\
\text { Sedimentação }\end{array}$ \\
\hline VCR05 & $17 \mathrm{~cm}$ & Beta 388510 & $1.770 \pm 30$ & {$[1.606-1.744]$} & 1.650 & \multirow{2}{*}{$\begin{array}{l}\text { Entre CR13 e CR05: } \\
0,66 \mathrm{~cm} / 100 \text { anos }\end{array}$} \\
\hline VCR07 & $25 \mathrm{~cm}$ & Beta 432596 & $3.340 \pm 30$ & [3.450- 3.590] & 3.550 & \\
\hline VCR13 & $49 \mathrm{~cm}$ & Beta 388511 & $5.710 \pm 30$ & {$[6.410-6.567]$} & 6.500 & \multirow{3}{*}{$\begin{array}{l}\text { Entre CR23 e CR13: } \\
0,27 \mathrm{~cm} / 100 \text { anos }\end{array}$} \\
\hline VCR18 & $69 \mathrm{~cm}$ & Beta 432597 & $15.650 \pm 60$ & [18.755 - 18.945] & 18.850 & \\
\hline VCR23 & $89 \mathrm{~cm}$ & Beta 359715 & $17.520 \pm 70$ & [20.907 - 21.425] & 21.150 & \\
\hline
\end{tabular}


ram observados os primeiros registros de Peperomia (1,5\%), Tipo Senecio (0,9\%), Euphorbiaceae Tipo 1 (0,8\%), Hedyosmum (0,7\%), Sapium (0,4\%), Tipo Aspilia $(0,4 \%)$, Drosera $(0,2 \%)$, Hydrocotyle $(0,2 \%)$, Mimosa $(0,2 \%)$, Maprounea $(0,2 \%)$, Apocynaceae Tipo 1 (0,2\%), Begonia (0,1\%), Tipo Trixis $(0,1 \%)$. Com percentuais menores, ocorreram Alternanthera (0,07\%), Cuphea $(0,03 \%)$ e Tipo Alchornea (0,03\%). Como verificado no Intervalo VCR I a vegetação herbáceo-arbustiva continuou sendo a mais representativa, e apresentou um percentual de 80,4\%.

A vegetação arbórea mostrou um declínio na porcentagem de Ilex sp. (0,8\%) e desaparecimento de Podocarpus e Drymis brasiliensis. Em contrapartida, foi registrado um aumento considerável no percentual do gênero Roupala (de 1,85\% para 7\%), não houve alteração para o gênero Myrsine (0,2\%). Ainda dentre as espécies arbóreas, foi registrado aumento nos percentuais dos gêneros: Euplassa (2,0\%), Daphnopsis (1,0\%), Cecropia (0,9\%), Tipo Eremanthus $(0,7 \%)$, Anacardiaceae Tipo $1(0,7 \%)$, Tipo Butia (0,7\%), Araliaceae Tipo 1(0,5\%) Ericaceae Tipo $1(0,6 \%)$ e Fabaceae Tipo $1(0,4 \%)$. Surgiram os táxons Pseudobombax $(0,4 \%)$,

Smilax (03\%), Stryphnodendron (0,03\%), Symplocaceae Tipo 1 (0,07\%), Tipo Campomanesia $(0,2 \%)$ e Tipo Senna $(0,07 \%)$ com o total de 18,37\% da vegetação arbórea para o Intervalo VCRII. Foi possível observar ainda, o registro dos gêneros Eryngium, Hedyosmum, Alternanthera e o Tipo Gnaphalium em menores percentuais.

Os pteridófitos foram representados no Intervalo VCRII principalmente pelos esporos de Lycopodiella cernua, Lycopodiella alopecuroides, Lycopodiella caroliniana, Cyathea Tipo 1, Schizae, Blechnum e Pteris e totalizaram 372 esporos na contagem complementar.

Dentre as algas foram registrados os mesmos táxons do intervalo anterior Spyrogira, Debarya e Mougeotia, além de Chlamydomonas.

\subsubsection{Intervalo VCRIII (26 - $00 \mathrm{~cm}$, amostras VCR07 a VCR01, de 3.550 anos cal. AP ao presente)}

Dentre a flora herbáceo-arbustiva, neste intervalo os percentuais de Poaceae continuaram representativos, porém em declínio (48\% a 36\%) como já observado no intervalo anterior. Permaneceram semelhantes ao intervalo anterior as porcentagens dos táxons Tipo Borreria $(3,5 \%)$, Tipo Senecio (0,8\%), Tipo Eupatorium (0,4\%) e Tipo Gnaphalium (0,3\%). Houve aumento nos percentuais dos táxons Tipo Baccharis (4,7\%), Peperomia $(3,4 \%)$, Solanum (2\%), Hedyosmum (1\%),
Begonia (0,4\%), Hydrocotyle (0,4\%), Mimosa $(0,4 \%)$, Apocynaceae Tipo $1(0,3 \%)$ e Alternanthera $(0,1 \%)$. Os gêneros Maprounea $(0,17 \%)$, Tipo Vernonia $(0,5 \%)$, Tipo Alchornea $(0,2 \%)$, Cuphea $(0,2 \%)$ e Polygala $(0,05 \%)$, voltaram a ocorrer neste intervalo. Os grãos de pólen típicos de vegetação herbáceo-arbustiva tiveram uma soma em torno de 67\%. Dentre os táxons arbóreos foram registrados Bignoniaceae Tipo 1 (0,3\%), Pouteria $(0,2 \%)$, Roupala (7\%), Euplassa (6\%), Tipo Butia $(1,2 \%)$, Ilex $(1,1 \%)$, Cecropia $(0,8 \%)$, Anacardiaceae Tipo 1 (0,4\%), Daphnopsis (0,5\%), Fabaceae Tipo $1(0,4 \%)$ e Araliaceae Tipo 1 (6\%). Os táxons que desapareceram em relação ao intervalo anterior foram Commiphora, Plenckia, Protium, Stryphnodendron e Symplocaceae Tipo 1.

Foi registrada a primeira ocorrência de $M a u$ ritia flexuosa (5\%) com considerável aumento nas porcentagens de Mauritia flexuosa em direção ao topo $(9,6 \%)$. Houve o aumento no registro dos táxons Cecropia, Anacardiaceae Tipo 1, Daphnopsis, Fabaceae Tipo 1, Araliaceae Tipo 1, Roupala, Tipo Eremanthus, Mimosa, Campomanesia, Pseudobombax e Eriotheca.

Os esporos de pteridófitos registrados foram Lycopodiella cernua, Lycopodiella caroliniana, Blechnum e Cyathea Tipo 1.

Dentre as algas, continuaram presentes Spyrogira e Mougeotia e Chlamydomonas.

\subsection{Análises isotópicas}

Os resultados dos teores de COT e NT-t, e valores de $\mathrm{C} / \mathrm{N}, \delta^{13} \mathrm{C}$ e $\delta^{15} \mathrm{~N}$, são apresentados na figura 9. Quando analisados do ponto de vista da caracterização paleoambiental, esses resultados permitem o estabelecimento dos teores de matéria orgânica e do nitrogênio no depósito sedimentar, das variações das condições mais ou menos úmidas do ambiente de sedimentação, identificação de plantas C3 e C4 e misturas, além da origem da matéria orgânica sedimentar em relação às plantas terrestres e/ou fitoplâncton.

Os valores de COT (Fig. 9A) das amostras do testemunho da Vereda Carrasco da Raposa variaram de $0,76 \%$ a $12,01 \%$. As amostras VCR26 a VCR24 (100 cm a $93 \mathrm{~cm}$ ) na base do perfil registraram valores entre $0,76 \%$ e $2,27 \%$, as amostras VCR23 a VCR12 (89 cm a $45 \mathrm{~cm}$ ) valores de 4,32\% a 9,82\%. Na amostra VCR11 (41 cm) o valor diminuiu e ficou próximo aos valores encontrados na base do testemunho, com 2,23\%. A partir da amostra VCR10 $(37 \mathrm{~cm})$ houve uma tendência de aumento progressivo nos valores de COT que variaram de 6,48\% a $12,01 \%$. 


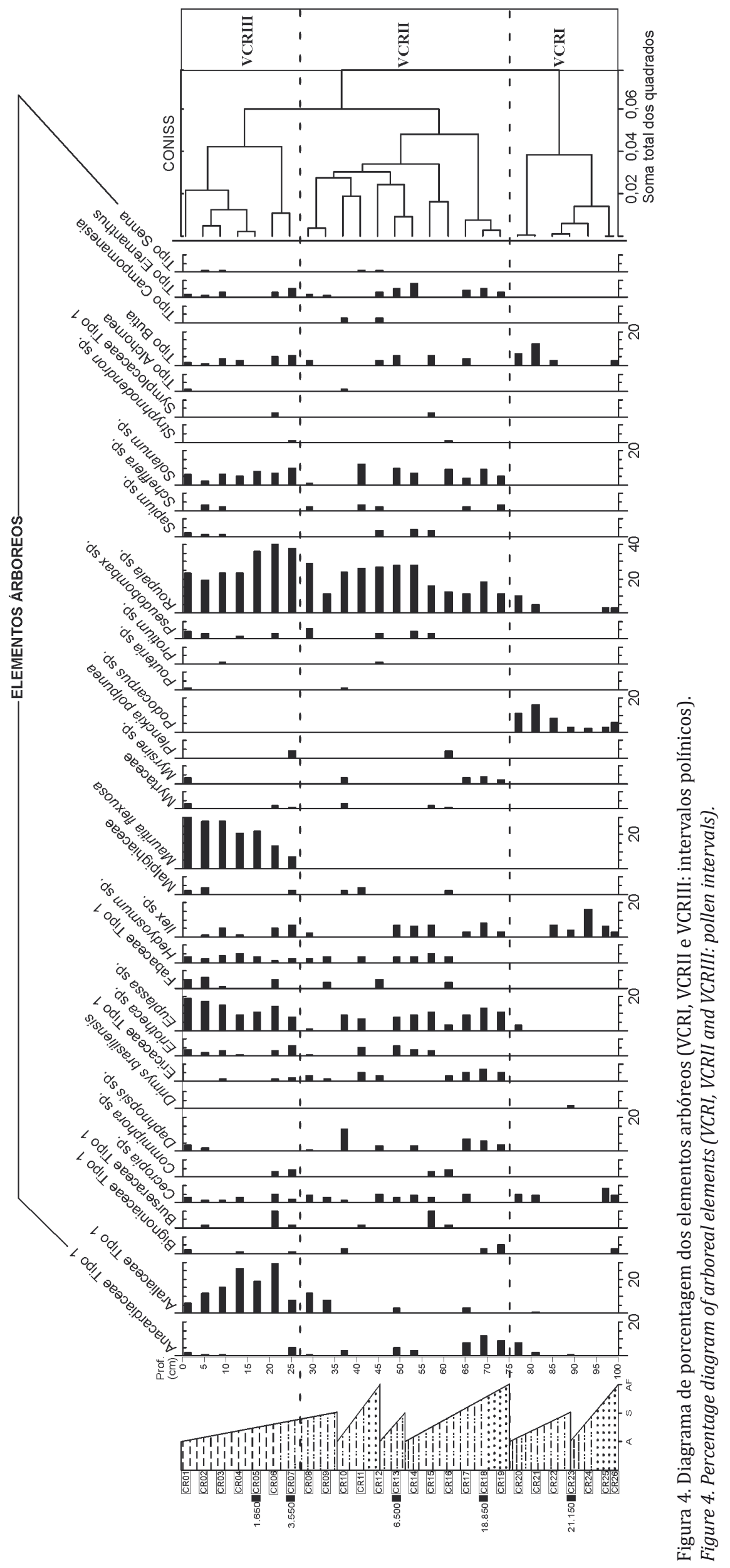




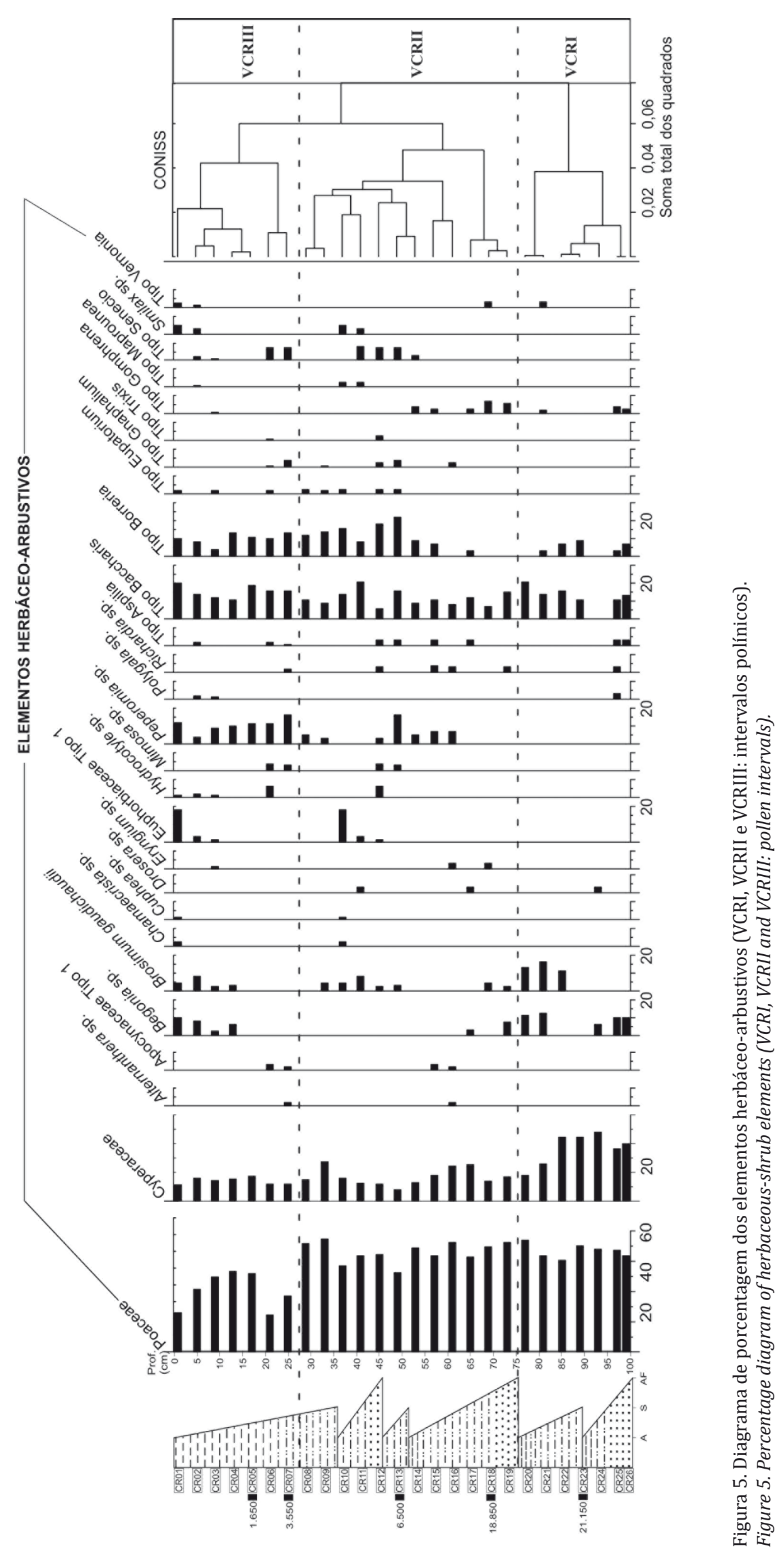




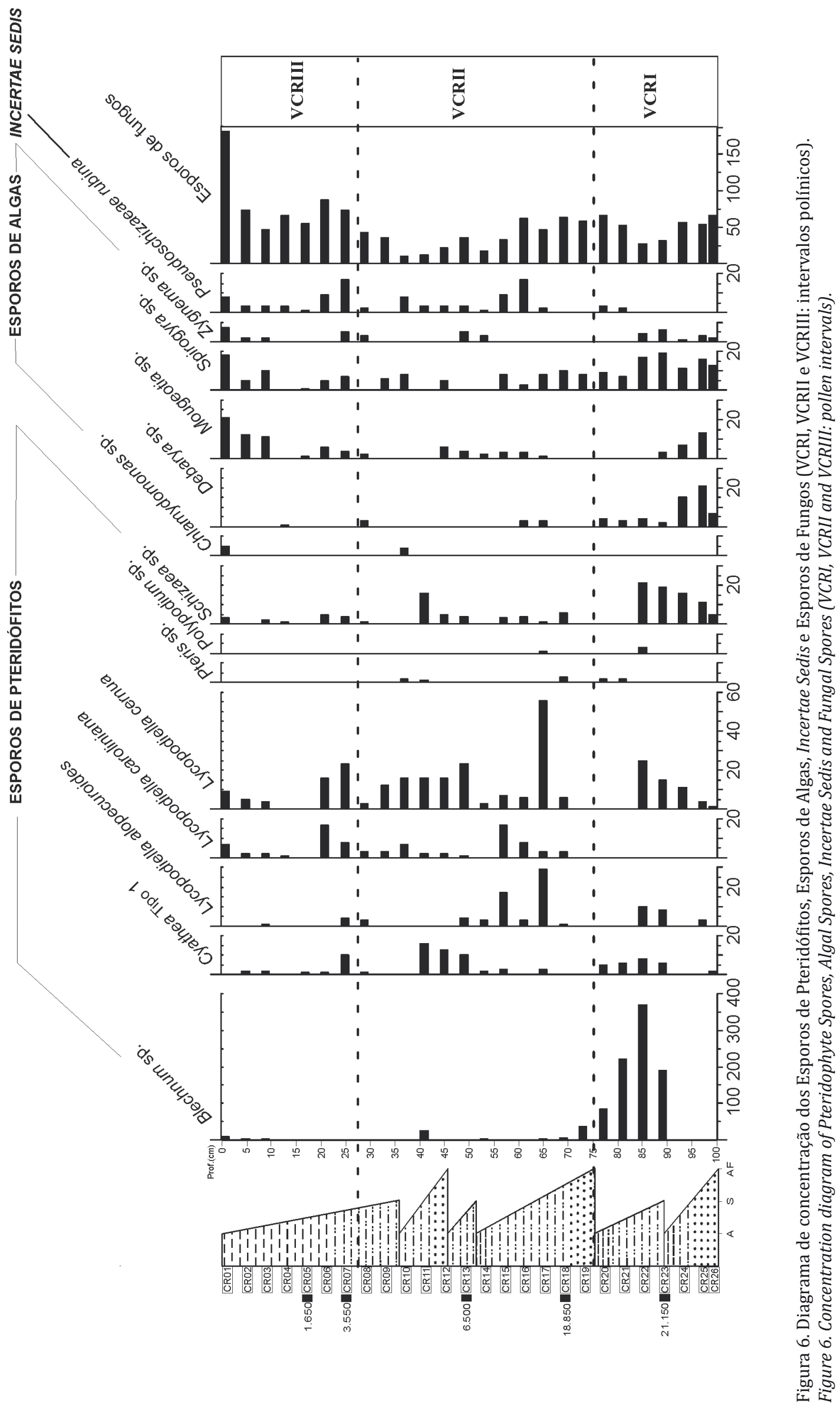




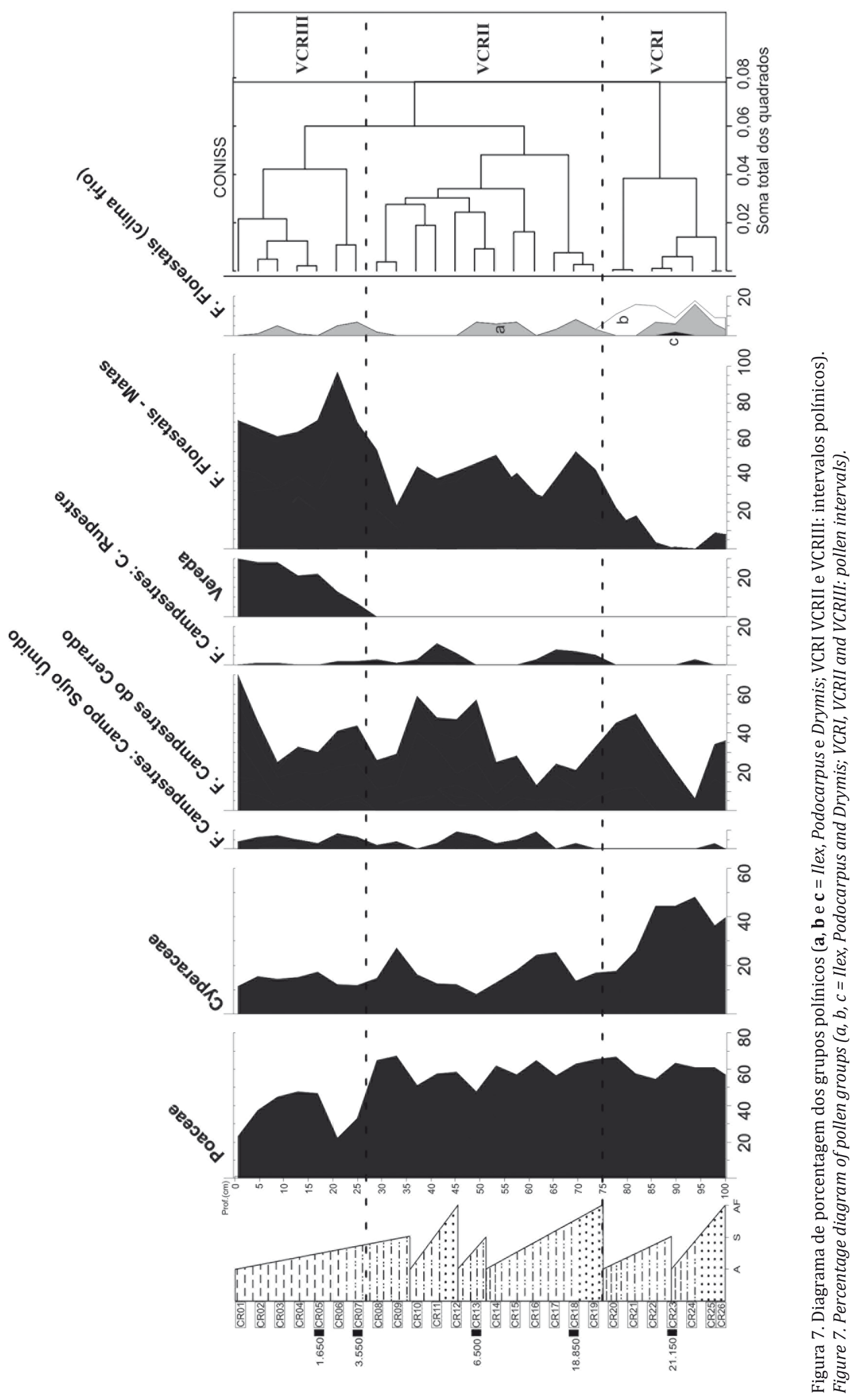




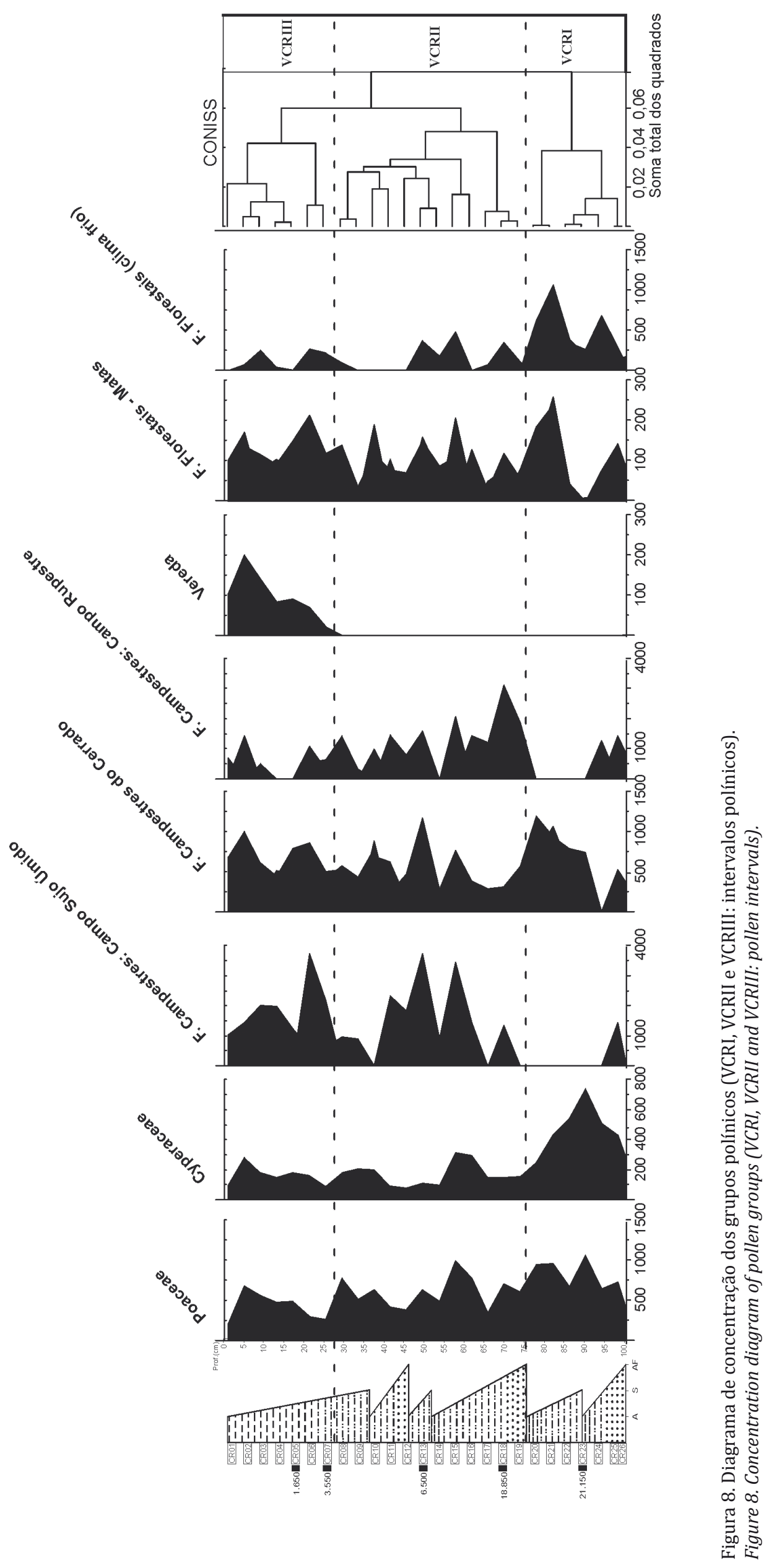




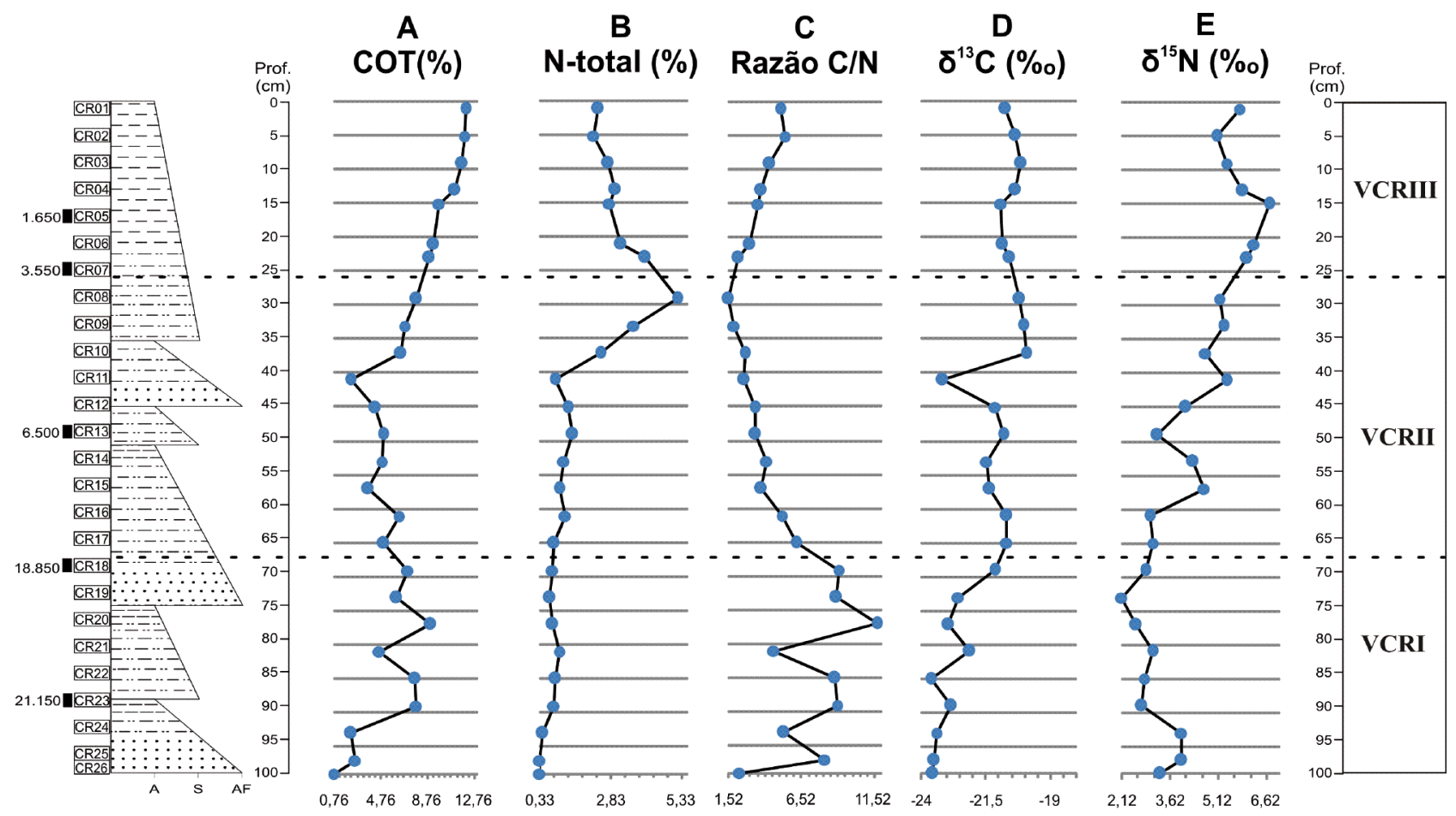

Figura 9. Perfil com curvas das análises isotópicas. A) COT (\%); B) N-total (\%); C) Razão C/N, D) $\delta^{13} \mathrm{C}(\% 0)$ e E) $\delta^{15} \mathrm{~N}(\% 0)(V C R I$, VCRII e VCRIII: intervalos polínicos).

Figure 9. Profile with curves of isotopic analysis. A) COT (\%); B) N-total (\%); C) Rate C/N, D) $\delta^{13} C\left(\%\right.$ ) and E) $\delta^{15} N(\%$ ) (VCRI, VCRII and VCRIII: pollen intervals).

Quanto aos teores de N-total (Fig. 9B), o conjunto de amostras da base VCR26 a VCR11 (100 $\mathrm{cm}$ a $41 \mathrm{~cm}$ ) apresentou uma média de $1,27 \%$, nas amostras VCR10 a VCR0 $8(37 \mathrm{~cm}$ a $29 \mathrm{~cm})$ houve uma elevação de 2,46\% - 5,15\%, e nas amostras VCR07 até VCR01 $(25 \mathrm{~cm}$ a $01 \mathrm{~cm})$ um declínio de $4,03 \%-2,38 \%$.

Os valores de C/N (Fig. 9C) entre as amostras VCR26 e VCR19 $(100 \mathrm{~cm}$ a $73 \mathrm{~cm})$ oscilaram de 2,30 a 11,65 com tendências crescentes e decrescentes. A partir da amostra VCR18 $(69 \mathrm{~cm})$ os valores de $\mathrm{C} / \mathrm{N}$ sofreram um declínio gradual em direção ao topo do perfil até a VCR08 $(29 \mathrm{~cm})$, que variou de 9,05 a 1,52. A partir da amostra VCR07 $(25 \mathrm{~cm})$, os valores de $\mathrm{C} / \mathrm{N}$ aumentaram de $2,22 \mathrm{a}$ 5,04 .

Os valores de $\delta^{13} \mathrm{C}$ (Fig. 9D) variaram de $-19,95 \%$ o a $-23,65 \%_{0}$. Na base do perfil, amostras VCR26 a VCR18 (100 cm a $69 \mathrm{~cm})$, os valores de $\delta 13 \mathrm{C}$ registrados foram de $-23,55 \%$ o a $-21,15 \%$; já entre as amostras VCR17 e VCR01 $(65 \mathrm{~cm}$ e $01 \mathrm{~cm})$, os valores se mantiveram em torno de $-20,79 \%$.

Os valores de $\delta^{15} \mathrm{~N}$ nas amostras VCR26 a VCR16 $(100 \mathrm{~cm}$ a $61 \mathrm{~cm})$ foram em torno de $3,30 \%_{0}$ e nas amostras VCR15 a VCR01 $(57 \mathrm{~cm}$ a $01 \mathrm{~cm}$ ) de $4,12 \%_{\text {o }}$ a $6,70 \%$ o (Fig. 9E).

\section{Discussão dos resultados}

A seguir estão representadas (Fig.10) as localizações de 17 sítios do bioma Cerrado, onde foram desenvolvidos estudos palinológicos e/ou isotópicos: Carajás (Absy et al., 1991), Lagoa de Serra Negra (De Oliveira, 1992), Lagoa Olhos d'Água (De Oliveira, 1992; Raczka et al., 2012), Turfeira de Salitre (Ledru, 1993), Lago do Pires (Behling, 1995), Vereda de Cromínia (Ferraz-Vicentini \& Salgado-Labouriau, 1996), Lagoa Santa (Parizzi et al., 1998), Vereda de Águas Emendadas (Barberi et al., 2000), Lagoa da Confusão (Behling, 2002), Lagoa Nova (Behling, 2003), Lagoa do Caçó (Ledru et al., 2006), Lagoa dos Mares (Raczka et al., 2012), Turfeira Pau-de-Fruta (Horák, 2009), Vereda Urbano (Lorente et al., 2010), Vereda Laçador (Cassino \& Meyer, 2013), Vereda Juquinha/Cuba (Pires, 2014) e Vereda Carrasco da Raposa (este trabalho). A figura 11 apresenta um esquema com a variação da umidade nesses 17 sítios.

\subsection{VCRI - 21.150 a 18.850 anos cal. AP}

Neste intervalo de tempo, na Vereda Carrasco da Raposa não foram registrados grãos de pólen de Mauritia flexuosa o que pode estar associado ao ambiente mais frio que o atual e permite afirmar que a vereda ainda não havia se estabelecido no local. 0 conjunto de elementos herbáceos-arbustivos 
registrados caracterizou uma fitofisionomia típica das Formações Campestres do Cerrado, composta por arbustos e subarbustos esparsos. Houve registro dos táxons arbóreos Podocarpus, Ilex, Drymis e Ericaceae, a associação destes táxons indica condições climáticas mais frias do que as atuais (Salgado-Labouriau, 1994; Mendonça et al., 2008).

Entre 19.000 e 11.500 anos AP, os registros palinológicos do Cerrado mostraram em linhas gerais que houve uma estação seca prolongada com condições climáticas mais frias do que as atuais nas localidades onde as altitudes variam de $700 \mathrm{a}$ 1100 m, como em Cromínia (GO), Lagoa dos Olhos d' Água (MG), Carajás (PA), Águas Emendadas (DF) e Buritizeiro (MG) (Absy et al., 1991; De Oliveira, 1992; Ferraz-Vicentini \& Salgado-Labouriau, 1996; Barberi et al., 2000; Lorente et al., 2010; Raczka et al., 2012) . Entretanto condições climáticas mais úmidas e mais frias do que as atuais foram registradas na Turfeira de Salitre por Ledru (1993) e em Lagoa de Serra Negra por De Oliveira (1992).

Neste período as características da vegetação e ausência dos buritis na Vereda Carrasco da Raposa sugerem que as condições ambientais durante o final do Pleistoceno e início do Holoceno eram mais secas, porém com umidade suficiente para a formação de zonas úmidas. As mesmas condições foram observadas nos registros de Carajás (Absy et al., 1991), Lagoa de Serra Negra (De Oliveira, 1992), Cromínia (Ferraz-Vicentini \& Salgado-Labouriau, 1996), Águas Emendadas (Barberi et al., 2000), Turfeira Pau-de-Fruta (Horák, 2009), Vereda Urbano (Lorente et al., 2010), Vereda Laçador (Cassino \& Meyer, 2013) e Vereda Juquinha/Cuba (Pires, 2014). Nestes locais, assim como na Vereda VCR, foi registrada a ocorrência de ambientes úmidos e/ou encharcados e de clima frio, com presença de grãos de pólen provenientes de ervas higrófitas e plantas aquáticas como Drosera, Cyperaceae, Eryngium, associados a táxons indicativos de temperaturas mais frias como Drymis brasiliensis, Podocarpus, Ilex e Ericaceae.

Os dados isotópicos corroboraram a presença de um ambiente úmido na Vereda Carrasco da Raposa. Na base do perfil sedimentar da vereda $(89 \mathrm{~cm}-68 \mathrm{~cm})$, de 21.150 a 18.850 anos cal. AP, os valores do sinal isotópico do carbono $(\delta 13 \mathrm{C})$ foram de $-24 \%$ a $-21,5 \%$. Esses valores indicam predomínio de plantas C3, com provável mistura de plantas $\mathrm{C} 4$. Já os valores de $\mathrm{C} / \mathrm{N}$ variaram de 1,5 a 11,5 e indicam predomínio de algas na MO. Os valores de $\delta 15 \mathrm{~N}$ foram de $3,5 \%$ a $\sim 1,0 \%$ o que representa mistura de matéria orgânica de algas e plantas terrestres.

Este mesmo padrão foi observado por Horák (2009) na Turfeira Pau-de-Fruta, em torno de

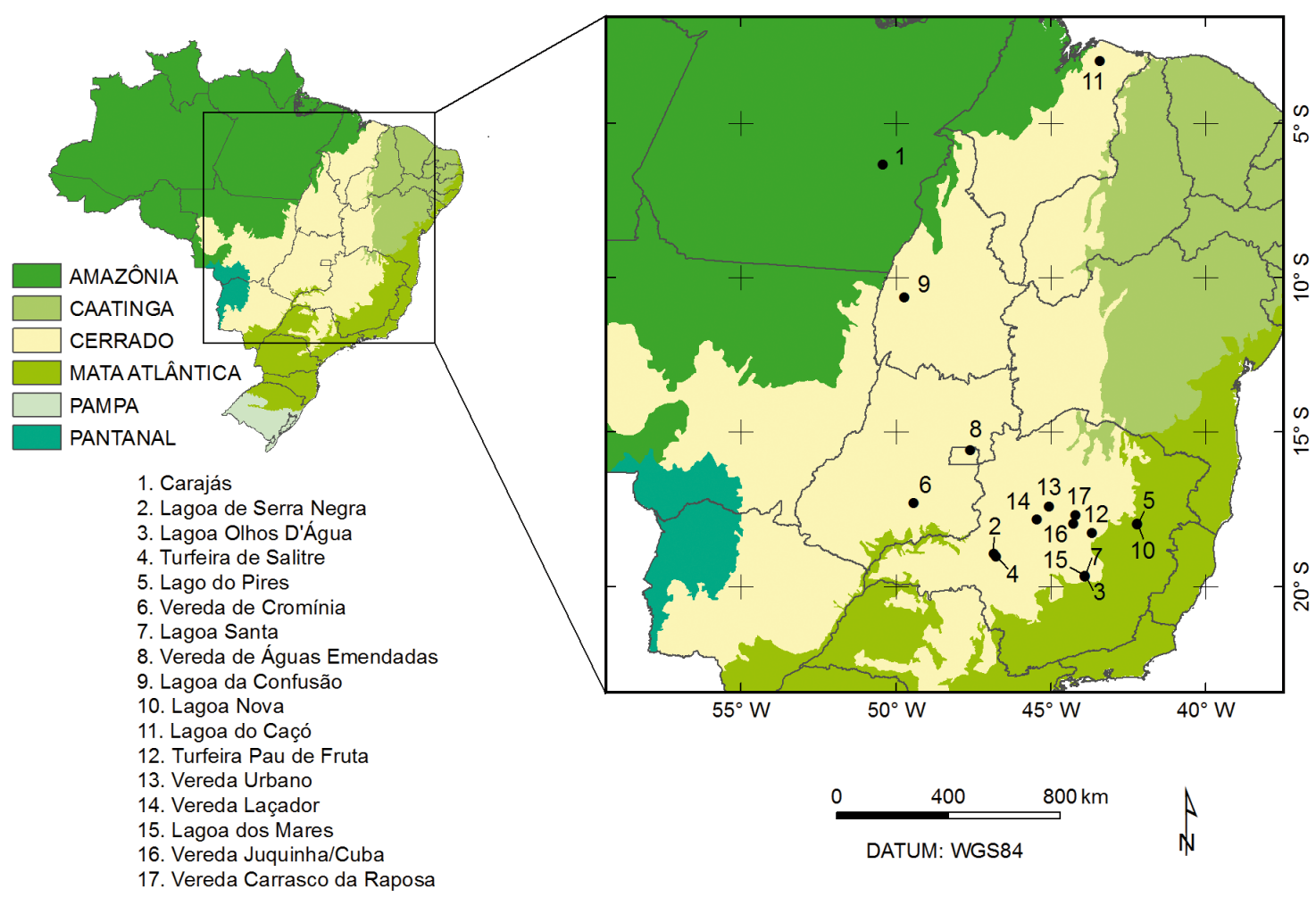

Figura 10. Localização de 17 sítios no Bioma Cerrado, onde foram desenvolvidos estudos palinológicos e/ou isotópicos (modificado de Meyer et al., 2014).

Figure 10. Location of 17 sites in the Cerrado, which were developed palynological and/or isotopic studies (modified of Meyer et al., 2014) 


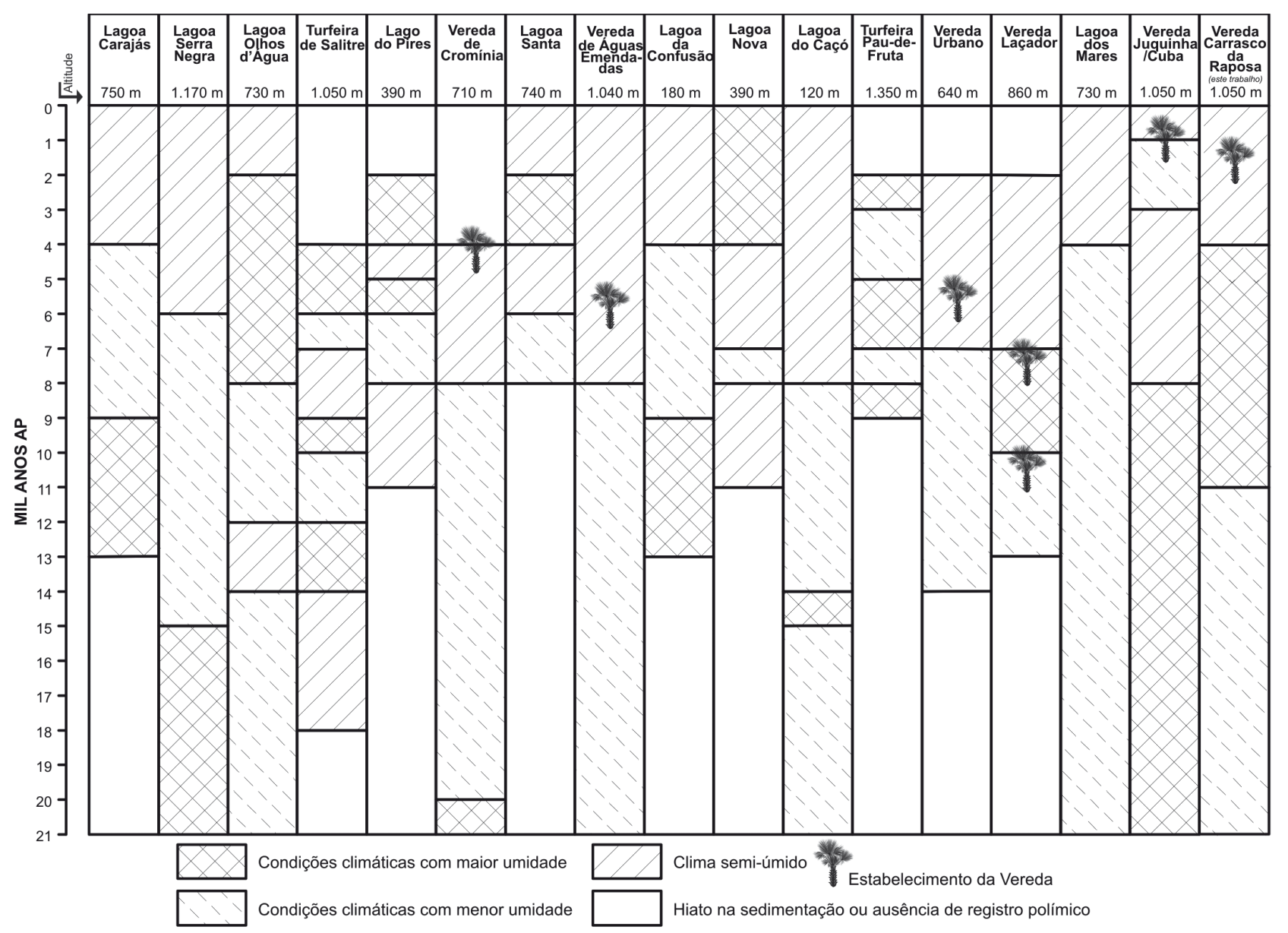

Figura 11. Representação esquemática da variação da umidade nos 17 sítios estudados no Bioma Cerrado (modificado de Salgado-Labouriau et al., 1997).

Figure 11. Schematic representation of the humidity variation in the 17 sites studied in the Cerrado (modified of Salgado-Labouriau et al., 1997)

20.350 anos AP. Os valores do sinal isotópico de $\delta 13 \mathrm{C}$ iguais a $-20,9 \%$ corroboram o desenvolvimento da Mata (C3) e do Campo Rupestre (C3 e CAM) no topo dos morros em meio à vegetação campestre (C4). Já na região do Cerrado no estado de São Paulo, Souza et al. (2013) observaram há cerca de 10.000 anos AP, valores de $\delta 13 \mathrm{C}$ por volta de $-14,24 \%$ o que representam o predomínio de plantas C4, e sugerem redução da umidade próximo ao limite Pleistoceno Superior - Holoceno Inferior.

No que diz respeito à fitofisionomia predominante, indicada pelos dados da análise palinológica e isotópica, estima-se que havia um mosaico vegetacional de Formações Campestres do Cerrado que circundavam os elementos das Formações Florestais - Matas.

\subsection{VCRII - 18.850 a 3.550 anos cal. AP}

No início do Holoceno foram observadas de maneira geral, condições climáticas mais quentes, como resultado do aumento das temperaturas depois do UMG, além de variações na circulação atmosférica que culminaram em mudanças na vegetação em todo o Bioma Cerrado (Salgado-Labouriau, 1997).

Neste intervalo de tempo, na Vereda Carrasco da Raposa as mudanças da vegetação observadas foram marcadas pelo registro de novos táxons herbáceo-arbustivos que evidenciaram a diversidade das Formações Campestres do Cerrado. A fitofisionomia com características de vegetação mais aberta, identificada na base do perfil, deu lugar um mosaico composto por Formações Campestres do Cerrado com Campo Sujo Úmido e Campo Rupestre.

Houve considerável aumento e surgimento de elementos arbóreos típicos das Formações Florestais como Roupala, Euplassa, Daphnopsis, Tipo Eremanthus, Myrsine, Smilax, Stryphnodendron, Symplocaceae, Campomanesia, Senna, Anacardiaceae, Araliaceae e Fabaceae provavelmente devido ao aumento da temperatura após o UMG.

Foi possível observar a associação dos gêneros Eryngium, Hedyosmum, Alternanthera e o Tipo 
Gnaphalium, que sugere ambientes encharcados ou muito úmidos (Ribeiro \& Walter, 2008).

Dentre as algas foram registrados os mesmos táxons do intervalo anterior Spyrogira, Debarya, Mougeotia e Chlamydomonas, o que confirma a presença de lâmina d'água no ambiente deposicional.

Diferente do que ocorreu na região da Serra do Cabral, em Carajás, Águas Emendadas, Cromínia, Lagoa Olhos d'Água e em Lagoa Santa o máximo da fase seca no Cerrado do Brasil Central perdurou até cerca de 7.000 anos AP (Absy et al., 1991; De Oliveira, 1992; Ferraz-Vicentini \& Salgado-Labouriau, 1996; Parizzi et al., 1998; Barberi et al., 2000; Raczka et al., 2012).

Após esta fase seca, no Brasil central uma fase relativamente menos seca ocorreu a partir de 5.000 anos AP, onde houve registros de chuvas torrenciais, deslizamentos de terra e grandes depósitos aluviais que culminaram na formação de lagos, charcos e veredas. Dessa forma, o clima passou a ser semi-úmido com uma estação seca prolongada de três a cinco meses e continuou até o presente (Salgado-Labouriau, 1997).

Na margem esquerda do Rio São Francisco e na região do Chapadão dos Gerais os estudos realizados na Vereda Urbano (Lorente et al., 2010) e na Vereda Laçador (Cassino \& Meyer, 2013) evidenciaram o início de uma fase mais úmida em torno dos 6.000 anos AP para a primeira, e entre 9.000 a 7.000 anos cal. AP para a segunda através do registro do estabelecimento da vereda.

Na Vereda Carrasco da Raposa, por volta de 6.500 anos cal. AP $(\sim 48 \mathrm{~cm})$ houve um aumento na deposição de areia no registro sedimentar, possivelmente devido ao aumento da zona encharcada na borda da vereda, e consequente redução da matéria orgânica no sedimento o que resultou em um empobrecimento do carbono total, com valores de COT iguais a 2,23\% (Fig. 9A). Os valores de $\mathrm{C} / \mathrm{N}$ da MO variaram de $<6$ a 1,5 com predomínio de algas e umidade local. Os valores de $\delta 13 \mathrm{C}$ ficaram entre de $-19,5 \%$ o $(\sim 35 \mathrm{~cm})$ a $-23,5 \%$ o $(\sim 41 \mathrm{~cm})$ e indicaram predomínio de plantas $\mathrm{C} 4$ com provável mistura com plantas C4 (Fig. 9D). Os teores de $\delta 15 \mathrm{~N}$ ficaram em torno de $4,5 \%$ a $\sim 5 \%$, ou seja, houve mistura de algas e plantas terrestres na MO. Esse resultado também foi observado por Horák (2009), na Turfeira Pau-de-Fruta, porém por volta de 9.400 anos AP e por Souza et al. (2013) no estado de São Paulo, onde no período de 2.100 anos cal. AP até os dias atuais os valores de $\delta 13 \mathrm{C}$ foram de aproximadamente $-20,26 \%$.

Na Turfeira Pau-de-Fruta, Horák (2009) entre 7.300 anos AP e 6.400 AP (idades interpoladas) as condições foram menos úmidas e os sinais isotópicos do carbono ( $\delta 13 \mathrm{C}$ ) tornaram-se mais enriquecidos e os do nitrogênio $(\delta 15 \mathrm{~N})$ mais empobrecidos, o que caracterizou o aumento da contribuição da vegetação campestre e a redução da contribuição algal no sedimento.

\subsection{VCRIII - 3.550 anos cal. AP ao presente}

Neste intervalo foi registrada a primeira ocorrência de Mauritia flexuosa, além de elementos herbáceos de Matas (Formações Florestais) e de locais encharcados como Peperomia, Hedyosmum, Hydrocotile, Tipo Trixis e Symplocos. Estes táxons, em conjunto com o surgimento de Mauritia, sugerem um aumento considerável da umidade local e o início da instalação da vereda no ambiente deposicional. Para que o buriti (Mauritia flexuosa) ocupe e colonize determinado local, é necessário que o clima seja quente e úmido, com valores de precipitação superiores a $1.000 \mathrm{~mm}$ anuais e solos permanentemente úmidos (Rull, 1998).

O aumento e surgimento no registro de táxons arbóreos como Cecropia, Anacardiaceae, Daphnopsis, Fabaceae, Araliaceae, Roupala, Tipo Eremanthus, Mimosa, Campomanesia, Pseudobombax e Eriotheca, confirmaram a presença da fitofisionomia típica do Cerrado, Formações Florestais - Matas, já observada desde o Intervalo VCRI.

Foram registrados e complementaram o panorama fitofisionômico os táxons: Hedyosmum, Symplocos, Hydrocotile e Araliaceae, comuns em regiões inundadas como bordas de Matas, áreas brejosas do Cerrado, em corpos d'água ou solos úmidos de forma emergente, flutuante ou anfíbia (Bauermann, 2003; Souza \& Lorenzi, 2005).

A partir de 3.500 anos cal. AP $(25 \mathrm{~cm})$, a porcentagem de Mauritia flexuosa aumentou significativamente e por volta de 1.650 anos cal. AP $(17 \mathrm{~cm})$ houve o estabelecimento da vereda no depósito do Carrasco da Raposa. Assim como na Serra do Cabral, em Águas Emendadas um período de clima mais úmido também foi registrado em aproximadamente 1.500 anos cal. AP, quando houve um pico de Mauritia flexuosa (Barberi et al., 2000). Na Lagoa da Confusão, a partir de 6.200 anos cal. AP, um aumento nos registros de árvores de Mata de Galeria indicou condições mais úmidas que as vigentes na primeira metade do Holoceno (Behling, 2002).

A ocorrência de elementos arbustivos e herbáceos, o aumento de árvores do Cerrado e o surgimento da palmeira Mauritia flexuosa, sugerem que as condições climáticas na Serra do Cabral entre $3.550(25 \mathrm{~cm})$ e 1.650 anos cal. AP $(17 \mathrm{~cm})$ se tornaram mais úmidas e quentes em relação aos pe- 
ríodos anteriores, com média pluviométrica anual acima de 1.000 mm e a duração da estação seca entre cinco e seis meses, condições estas semelhantes aos dias atuais para a região.

Segundo Meyer et al. (2014) nas Veredas de Águas Emendadas (DF), Cromínia (GO) e na Lagoa do Caçó (MA), o clima quente e semi-úmido, semelhante ao atual, se instalou há aproximadamente 8.000 anos cal. AP e permaneceu até o presente. De acordo com Behling (2002), na Lagoa da Confusão (TO), foi a partir de 6.200 anos cal. AP, que houve uma maior quantidade de árvores de Mata de Galeria e possíveis condições climáticas mais úmidas que as vigentes na primeira metade do Holoceno.

Na Vereda Carrasco da Raposa, em torno de 4.100 anos cal. AP $(33 \mathrm{~cm})$ houve uma queda na razão $\mathrm{C} / \mathrm{N}$, os valores variaram de 1,5 a 6 (Fig. 9C). Valores muito baixos da razão $\mathrm{C} / \mathrm{N}(\geq 3)$ evidenciam a presença de ambientes alagados e por isso com maior influência algal na composição da matéria orgânica depositada no sedimento. Este dado associado ao aumento considerável nas porcentagens de Mauritia flexuosa desse intervalo corrobora o surgimento e estabelecimento da vereda, que por sua vez, só se desenvolve em ambientes encharcados.

\section{Conclusões}

Os resultados da análise palinológica da Vereda Carrasco da Raposa, associados às datações $14 \mathrm{C}$, aos dados isotópicos e ao significado ambiental dos palinomorfos identificados, possibilitaram estabelecer as condições paleoambientais e paleoclimáticas a partir de 21.150 anos cal. AP no contexto do Último Máximo Glacial até o presente na região da Serra do Cabral.

No que diz respeito às condições paleoclimáticas na Vereda Carrasco da Raposa, os resultados mostraram em linhas gerais que no período de 21.150 a 18.850 anos cal. AP o clima era mais frio que o atual, devido à presença de elementos arbóreos como Podocarpus, Ilex, Drymis e Ericaceae no registro polínico. Após 18.850 até 3.550 anos cal. AP o clima ficou mais quente e mais úmido. A partir de 1.650 anos cal. AP o padrão climático registrado foi semelhante ao atual (clima semi-úmido) em direção ao topo do perfil, provavelmente com média pluviométrica anual acima de $1.000 \mathrm{~mm}$ e a duração da estação seca entre cinco e seis meses.

Quanto às mudanças fitofisionômicas na Serra do Cabral, foi observada uma sucessão da vegetação com predomínio de Formações Campestres: Campo Sujo Úmido e Campo Rupestre, associadas a traços de Formações Florestais (de clima frio) na base do perfil de 21.150 a 18.850 anos cal. AP, Campo Sujo Úmido e Campo Rupestre, associadas a elementos de Mata (Formações Florestais) típicos do Cerrado na porção mediana do perfil de 18.850 a 3.550 anos cal. AP. Em direção ao topo houve o estabelecimento da vereda a partir de 1.650 anos cal. AP.

Por meio de dados isotópicos e elementares do $\delta^{13} \mathrm{C}$ e $\delta^{15} \mathrm{~N}$ associados às datações $14 \mathrm{C}$ e intervalos polínicos, foi possível observar evidências de que durante o final do Pleistoceno e início do Holoceno na região da Serra do Cabral, houve constantes flutuações na umidade e nas condições climáticas que refletiram no desenvolvimento e composição da vegetação da Vereda Carrasco da Raposa.

Agradecimentos - Este trabalho é parte integrante da tese de doutoramento desenvolvida pela primeira autora junto ao Programa de Pós-Graduação em Geologia da UFMG, realizado no âmbito do projeto "Reconstituição da Vegetação Quaternária da Serra do Cabral, Minas Gerais, através de Estudos Palinológicos" com recursos da FAPEMIG (APQ 01697-11, FAPEMIG, Demanda Universal, 2012-2014). A primeira autora agradece à CAPES pela concessão de bolsa de doutorado. Os autores agradecem ao IEF pela concessão de licença de pesquisa no Parque Estadual da Serra do Cabral (SIGED - IEF/DPBIO/GPROP - 03921012013).

\section{Referências}

Ab'Saber, A.N. 1971. Contribuição à Geomorfologia da área dos Cerrados. In: Simpósio sobre o Cerrado. Resumos expandidos. São Paulo, EDUSP, p. 97-103.

Absy, M.L., Cleef, A., Fournier, M., Martin, L., Servant, M., Sifeddine, A., Silva, M.F.D.A., Soubies, F., Suguio, K., Turcq, B. \& Van der Hammen, T. 1991. Mise em évidence de quatre phase d'ouverture de la forêt dense dans Le sud-est de l'Amazonie au cours dês 60.000 dernieres années. Premiere comparaison avec d'áutres régions tropicales. Comptes Rendus Academie des Sciences Paris, 312: 673-678.

Barberi, M., Salgado-Labouriau, M.L. \& Suguio, K. 2000. Paleovegetation and paleoclimate of "Vereda de Águas Emendadas", central Brazil. Journal of South American Earth Sciences, 13: 241-254.

Barth, O.M. \& Melhem, T.S. 1988. Glossário ilustrado de palinologia. Campinas, Editora da Unicamp, 77p.

Bauermann S.G. 2003. Análises palinológicas e evolução paleovegetacional e paleoambiental das turfeiras de Barrocadas e Águas Claras, Planície Costeira do Rio Grande do Sul, Brasil. Porto Alegre, 137p. Tese de Doutorado, Programa de Pós-Graduação em Geociências, Instituto de Geociências, Universidade Federal do Rio Grande do Sul.

Bauermann, S.G., Radaeski, J.N., Evaldt, A.C.P., Queiroz, E.P. , Mourelle, D., Prieto, A. \& Silva, C.I. 2013. Pólen nas angiospermas diversidade e evolução. Canoas, 
Editora da ULBRA, v. 1, 216p.

Behling, H. 1995. A high resolution Holocene pollen record from Lago do Pires, SE Brazil: vegetation, climate and fire history. Journal of Paleolimnology, 4(3): 253-268.

Behling, H. 2002. Late Quaternary vegetation and climate dynamics in southeastern Amazonia inferred from Lagoa da Confusão in Tocantins State, Northern Brazil. Amazoniana, 17(1/2): 27-39.

Behling, H. 2003. Late glacial and Holocene vegetation, climate and fire history inferred from Lagoa Nova in the southeastern Brazilian lowland. Vegetation History and Archaeobotany, 12: 263-270.

Boutton, T.W. 1996. Stable carbon isotope ratios of soils organic matter and their use as indicators of vegetation and climate change. In: Boutton, T. W., Yamasaki, S.I. (Ed.). Mass spectrometry of soils. New York, Marcel Dekker, p. 47-82.

Cassino, R.F. 2011. Reconstituição da vegetação e do clima do Chapadão dos Gerais durante o Holoceno, a partir da análise palinológica da vereda Laçador. Belo Horizonte, 215p. Dissertação de Mestrado, Programa de Pós-Graduação em Geologia, Universidade Federal de Minas Gerais.

Cassino, R.F. \& Meyer, K.E.B. 2013. Reconstituição Paleoambiental do Chapadão dos Gerais durante o Quaternário Tardio, a partir da Análise Palinológica da Vereda Laçador. Revista Brasileira de Paleontologia, 16(1): 127-146.

Colinvaux P., De Oliveira, P.E. \& Patino, J.E.M. 1999. Amazon Pollen Manual and Atlas/Manual e Atlas Palinologico da Amazônia.Amsterdam, Harwood Academic Publishers, 322p.

De Oliveira, P.E. 1992. A palynological record of Late Quaternary vegetational and climatic change in southeastern Brazil. Ohio, 238p. Ph.D. thesis., The Ohio State University.

EMBRAPA. Empresa Brasileira de Pesquisas Agropecuárias. 2008. Disponível em: <https://www.embrapa. br>. Acesso em: 11 jan. 2013.

Faegri K. \& Iversen J. 1989. Textbook of Pollen Analysis. New York, Hafner Pub., 486p.

Ferraz-Vicentini, K.R. \& Salgado-Labouriau, M.L. 1996. Palynological analysis of a palm swamp in central Brazil. Journal of South American Earth Science, 9(3/4): 207-219.

Geominas, 1996a. Mapa de Precipitação Média Anual de Minas Gerais. Zoneamento Agroclimático de Minas Gerais. Disponível em: <http://www.geominas. mg.gov.br>. Acesso em: 26 jun. 2016

Geominas, 1996b. Mapa de Temperatura Média Anual de Minas Gerais. Zoneamento Agroclimático de Minas Gerais. Disponível em: <http://www.geominas. mg.gov.br>. Acesso em: 26 jun. 2016

Grimm, E.C. 1987. Coniss: a 77 program for stratigraphically constrained cluster analysis by the method of incremental sum of squares. Computers \& Geoscience, 13: 13-35.

Horák, I. 2009. Relações pedológicas, isotópicas e palinológicas na reconstrução paleoambiental da turfeira da Área de Proteção Especial (APE) Pau de Fruta, Ser- ra do Espinhaço Meridional. São Paulo, 203p. Dissertação de Mestrado, Escola Superior de Agricultura 'Luiz de Queiroz', Universidade de São Paulo.

IEF. Instituto Estadual de Florestas. 2009. Disponível em: <http://www.ief.mg.gov.br/areas-protegidas/210>. Acesso em: 14 set. 2013.

Ledru, M.P. 1993. Late Quaternary Environmental and Climatic Changes in Central Brazil. Quaternary Research, 39(1): 90-98.

Ledru, M.P., Ceccantini, G., Gouveia, S.E.M., López-Sáez, J.A., Pessenda, L.C.R. \& Ribeiro, A.S. 2006. Millenial-Scale Climatic and Vegetation Changes in a Northern Cerrado (Northeast, Brazil) since the Last Glacial Maximum. Quaternary Science Reviews, 25: 1110-1126.

Lopes, T.C. 2012. O Supergrupo Espinhaço na Serra do Cabral, Minas Gerais: contribuição ao estudo de proveniência sedimentar. Belo Horizonte, 116p. Dissertação de Mestrado, Programa de Pós-Graduação em Geologia, Universidade Federal de Minas Gerais.

Lorente, F.L. 2010. Análise palinológica da vereda da Fazenda Urbano, município de Buritizeiro, Minas Gerais, Brasil. Belo Horizonte, 230p. Dissertação de Mestrado, Programa de Pós-Graduação em Geologia, Universidade Federal de Minas Gerais.

Lorente, F.L., Meyer, K.E.B. \& Horn, A.H. 2010. Análise Palinológica da Vereda da Fazenda Urbano, Município de Buritizeiro, Minas Gerais, Brasil. Geonomos, 18(2): 57-72.

Mendonça, R.C., Felfili, J.M., Walter, B.M.T., Silva Júnior, M.C., Rezende, A.V., Figueira, J.S. \& Nogueira, P.E. 2008. Flora vascular do bioma Cerrado: um "checklist” com 11.430 espécies. In: Sano, S.M., Almeida, S.P. \& Ribeiro, J.F. (Ed.). Cerrado: Ecologia e Flora. v. 2. Brasília, Embrapa Informação Tecnológica, p. 4231279.

Meyer, K.E.B., Cassino, R.F., Lorente, F.L., Raczka, M. \& Parizzi, M.G. 2014. Paleoclima e paleoambiente do Cerrado durante o Quaternário com base em análises palinológicas. In: Carvalho, I. S., Garcia, M.J., Lana, C.C., Strohschoen, O. (Eds.). Paleontologia: Cenários da Vida, v. 5, Interciência, Rio de Janeiro, p. 403-420.

Meyers, P.A. 1994. Preservation of source identification of sedimentary organic matter during and after deposition. Chemical Geology, 114: 289-302.

O'Leary, M.H. 1988. Carbon isotopes in photosynthesis. Bioscience, 38: 328-336.

Parizzi, M.G., Salgado-Labouriau, M.L. \& Kohler, C.H. 1998. Genesis and environmental history of Lagoa Santa, SE Brazil. The Holocene, 8(3): 311-321.

Pessenda, L.C.R., Aravena, R.M. \& Melfi, A.J. 1996. The use of carbon isotopes (13C, 14C) in soil to evaluate vegetation changes during the Holocene in central Brazil. Radiocarbon, 38(2): 191-201.

Pessenda, L.C.R., Gouveia, S.E.M., Aravena, R., Boulet, R. \& Valencia, E.P.E. 2004. Holocene fire and vegetation changes in southeastern Brazil as deduced from fossil charcoal and soil carbon isotopes. Quaternary International, 114: 35-43.

Pires, G.L.P., 2014. Estudo palinológico da Vereda do Juquinha/Cuba, Parque Estadual da Serra do Cabral, 
Minas Gerais, Brasil. Belo Horizonte, 155p. Dissertação de Mestrado, Programa de Pós-Graduação em Geologia, Universidade Federal de Minas Gerais.

Punt, W., Hoen, P.P., Blackmore, S., Nilsson, S. \& Le Thomas, A. 2007. Glossary of pollen and spore terminology. Review of Palaeobotany and Palynology, 143: 1-81.

Raczka, M.F., De Oliveira, P.E., Bush, M. \& McMichael, C.H. 2012. Two paleoecological histories spanning the period of human settlement in southeastern Brazil. Journal of Quaternary Science, 28(2): 144-151.

Ribeiro, J.F. \& Walter, B.M.T. 2008. As principais fitofisionomias do bioma Cerrado. In: Sano S.M., Almeida S.P., Ribeiro J.F. (Ed.). Cerrado: Ecologia e Flora. v. 2. Brasília, Embrapa Informação Tecnológica, p. 151199.

Rull, V. 1998. Biogeographical and evolutionary consideration of Mauritia (Arecaceae), based on palynological evidence. Review of Palaeobotany and Palynology, 100: 109-122.

Salgado-Labouriau, M.L. 1973. Contribuição à Palinologia dos Cerrados. Rio de Janeiro, Academia Brasileira de Ciências, 291p.

Salgado-Labouriau, M.L. 1994. História ecológica da Terra. São Paulo, Edgard Blücher, 320p.

Salgado-Labouriau, M.L. 1997. Late Quaternary palaeoclimate in the savannas of South American. Journal of Quaternary Science, 12(5): 371-379.

Souza, M.M.D., Branco, F.R., Jasper, A. \& Pessenda, L.C.R. 2013. Evolução paleoambiental holocênica da porção nordeste do estado de São Paulo, Brasil. Revista Brasileira de Paleontologia, 16: 297-308.

Souza, V.C. \& Lorenzi, H. 2005. Botânica Sistemática. São Paulo, Instituto Plantarum, 608p.

Souza Filho, P.W.M. \& El-Robrini, M. 1995. Um exemplo de sistema deposicional dominado por macromaré: A Planície Costeira Bragantina - NE do Pará (Brasil). In: CONGRESSO DA ASSOCIAÇÃO BRASILEIRA DE ESTUDOS DO QUATERNÁRIO, 5, 1995, Niterói, Anais..., ABEQUA, p. 278-284.

Stockmar, J. 1971. Tablets spores used in absolute pollen analysis. Pollen et Spores, 13(4): 615-621.

Manuscrito 573

Editores: Marina Bento Soares \& Paulo A. Souza.
Stuiver, M. \& Reimer, P.J. 1993. Extended 14C Data Base and Revised Calib 3.0 14C Age Calibration Program. Radiocarbon, 35: 215-230.

Stute, M., Forster, M., Frischkorn, H., Serejo, A., Clark, J.F., Schlosser, P., Broecker, W.S. \& Bonani, G. 1995. Cooling of tropical Brazil (5oC) during the last glacial maximum. Science, 269: 379-383.

Tryon, R.M. \& Tryon, A.F. 1982. Ferns and allied plants. New York, Springer-Verlag, p. 25-39.

Uhlein, A. 1991. Transição cráton-faixa dobrada: um exemplo do Cráton do São Francisco e da Faixa Araçuaí (Ciclo Brasiliano) no estado de Minas Gerais. Aspectos estratigráficos e estruturais. São Paulo, 295p. Tese de Doutorado, Instituto de Geociências, Universidade de São Paulo.

Uhlein, A., De Trompette, R. \& Egydio-Silva, M. 1995. Rifteamentos superpostos e tectônica de inversão na borda sudeste do Cráton do São Francisco. Geonomos, 3: 99-107.

Uhlein, A., Alvarenga, C.J.S., De Trompette, R., Dupont, H.S.J.B., Egydio-Silva, M., Cukrov, N. \& Lima, O.N.B. 2004. Glaciação neoproterozóica sobre o cráton do São Francisco e faixas dobradas adjacentes. In: Mantesso-Neto, V., Bartorelli, A., Carneiro, C.D.R. \& Brito-Neves, B.B. (org.) Geologia do Continente Sul-Americano: evolução da obra de Fernando Flávio Marques de Almeida. Editora Beca, São Paulo, p. 539-553.

Viveiros, J.F.M. \& Walde, D. 1976. Geologia da Serra do Cabral, Minas Gerais, Brasil. Münsterische Forschungshefte Geologie und Paläontologie, 38/39: 15-27.

Walde, D. 1978. Desenvolvimento faciológico do Pré-cambriano entre a Serra Mineira e a Serra do Cabral (região sudoeste da Serra do Espinhaço, Minas Gerais). In: CONGRESSO BRASILEIRO DE GEOLOGIA, 30. 1978. Recife. Anais... Recife, (2): 711-725.

Ybert, J.P., Salgado-Labouriau, M.L., Barth, O.M., Lorscheitter, M.L., Barros, M.A., Chaves, S.A.M., Luz, C.F.P., Ribeiro, M., Scheel, R. \& Ferraz-Vicentini, K.R. 1992. Sugestões para padronização da Metodologia Empregada em Estudos Palinológicos do Quaternário. Revista do Instituto Geológico, 13(2): 47-49. 